\title{
Examining the Painful and Provocative Events Scale and Testing the Interpersonal-Psychological Theory of Suicidal Behavior in Undergraduates and Cyberbullying Victims
}

\author{
Matthew R. McNally \\ West Virginia University
}

Follow this and additional works at: https://researchrepository.wvu.edu/etd

\section{Recommended Citation}

McNally, Matthew R., "Examining the Painful and Provocative Events Scale and Testing the InterpersonalPsychological Theory of Suicidal Behavior in Undergraduates and Cyberbullying Victims" (2013). Graduate Theses, Dissertations, and Problem Reports. 106.

https://researchrepository.wvu.edu/etd/106

This Thesis is protected by copyright and/or related rights. It has been brought to you by the The Research Repository @ WVU with permission from the rights-holder(s). You are free to use this Thesis in any way that is permitted by the copyright and related rights legislation that applies to your use. For other uses you must obtain permission from the rights-holder(s) directly, unless additional rights are indicated by a Creative Commons license in the record and/ or on the work itself. This Thesis has been accepted for inclusion in WVU Graduate Theses, Dissertations, and Problem Reports collection by an authorized administrator of The Research Repository @ WVU. For more information, please contact researchrepository@mail.wvu.edu. 
Examining the Painful and Provocative Events Scale and Testing the Interpersonal-Psychological Theory of Suicidal Behavior in Undergraduates and Cyberbullying Victims

\author{
Matthew R. McNally
}

\author{
A Thesis \\ Submitted to the Eberly College of Arts and Sciences \\ at West Virginia University \\ in partial fulfillment of the requirement \\ for the degree of \\ Master of Science \\ in \\ Psychology \\ William Fremouw, Ph.D., Chair \\ Amy Fiske, Ph.D. \\ Aaron Metzger, Ph.D. \\ Department of Psychology
}

Morgantown, West Virginia

2013

Key Words: suicide, suicide-related behavior, painful and provocative events, cyberbullying victimization 


\begin{abstract}
Examining the Painful and Provocative Events Scale and Testing the Interpersonal-Psychological Theory of Suicidal Behavior in Undergraduates and Cyberbullying Victims
\end{abstract}

Matthew R. McNally

Suicide is a leading cause of preventable death in the United States. Individuals are hypothesized to acquire the capability for suicide through the experiencing of painful and provocative events. The primary purpose of this study was to assess the psychometric properties of the Painful and Provocative Events Scale (PPES), a measure that seeks to identify experiences that lead an individual to acquire the capability for suicide through an increased tolerance for pain and a decreased fear of death. An exploratory factor analyses conducted to examine the factor structure of a revised Painful and Provocative Events Scale yielded a two-factor structure. The results of a confirmatory factor analysis supported the two-factor structure. Hierarchical multiple regression analyses and a path analyses found support for the InterpersonalPsychological Theory of Suicide in a sample of undergraduates and a subsample of cyberbullying victims. 


\section{TABLE OF CONTENTS}

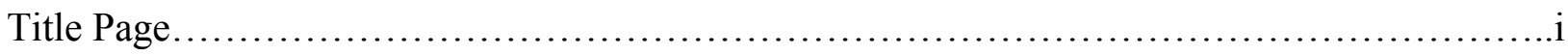

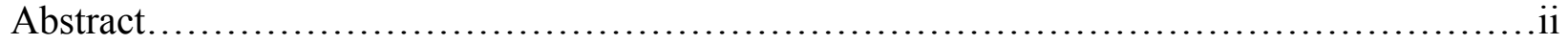

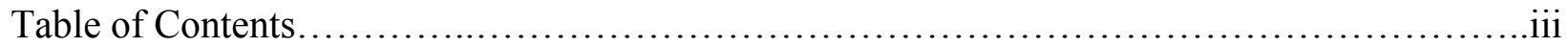

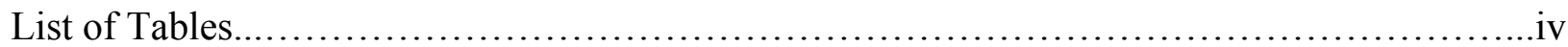

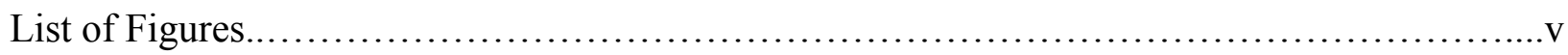

List of Appendices.................................................................

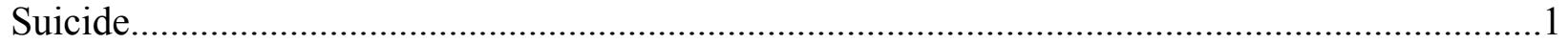

The Interpersonal-Psychological Theory of Suicidal Behavior .................................... 1

Instruments developed to test the IPTS .................................................................

Tests of the Interpersonal-Psychological Theory of Suicidal Behavior ............................5

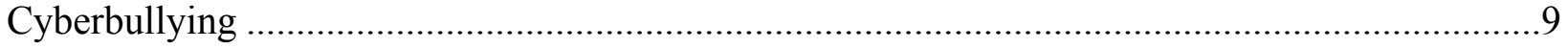

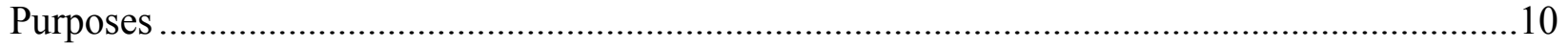

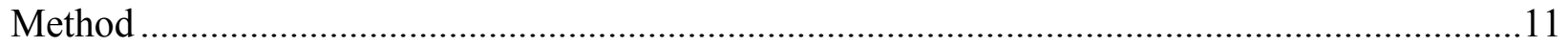

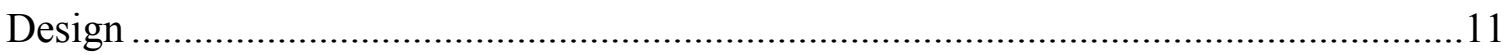

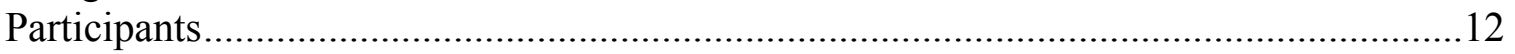

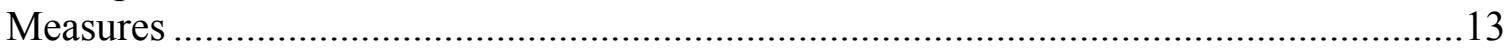

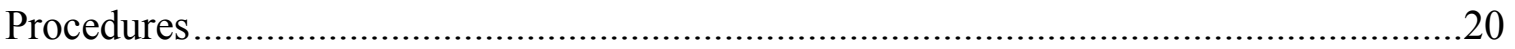

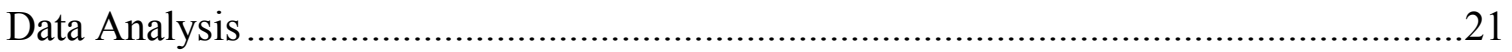

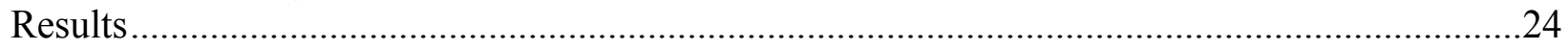

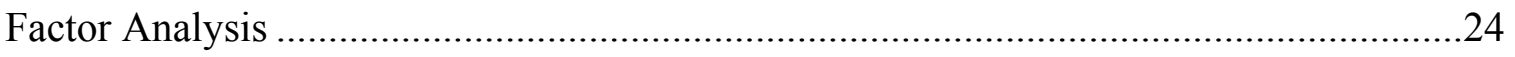

Tests of the Interpersonal-Psychological Theory of Suicidal Behavior ..........................25

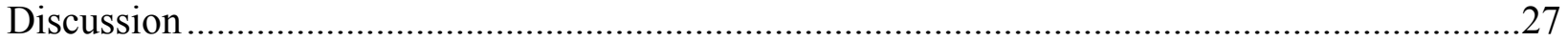

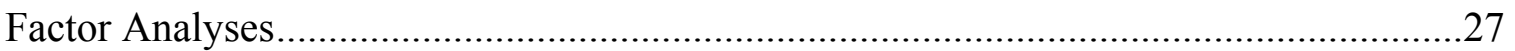

Implications for the Painful and Provocative Events Scale .............................................28

Hierarchical Regression Tests of IPTS ....................................................................29

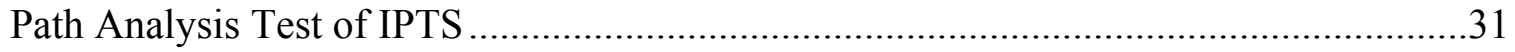

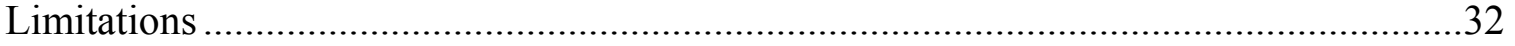

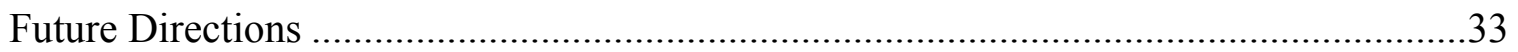

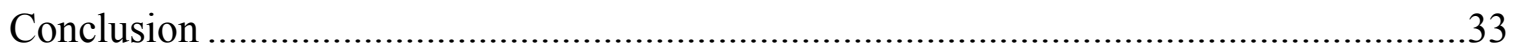

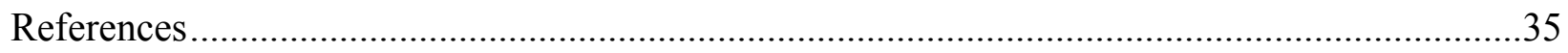

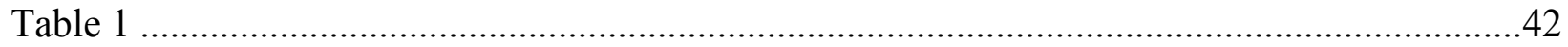

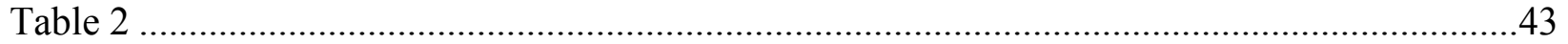

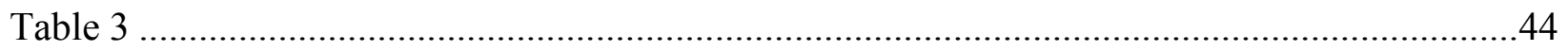

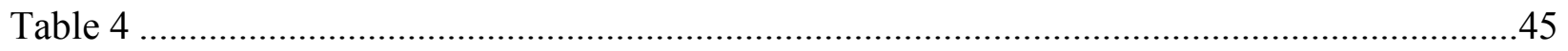

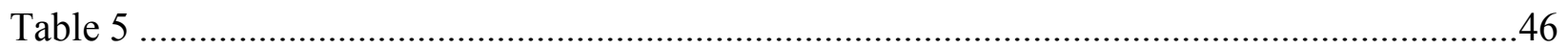

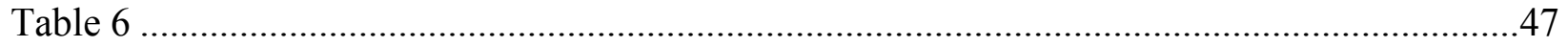

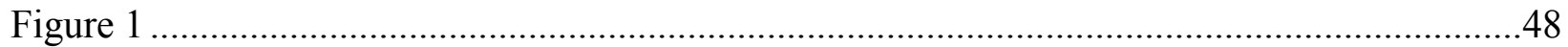

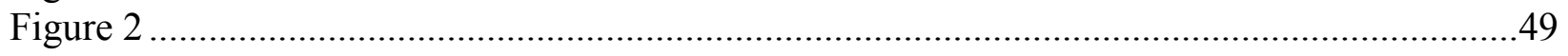

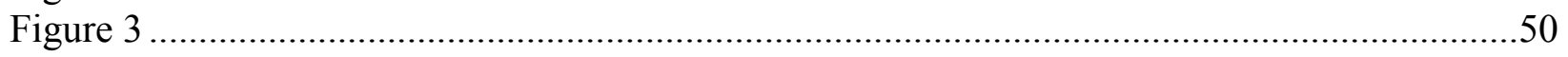

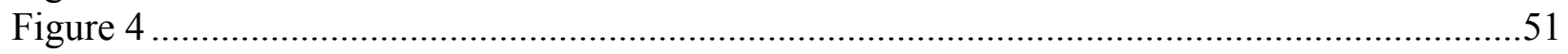

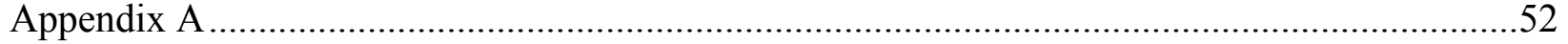

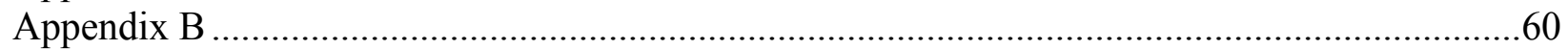




\section{LIST OF TABLES}

1. Demographic information of full sample and cyberbullying victim subsample. .42

2. Pattern Matrix of Factor Loadings for Exploratory Factor Analysis of Revised Painful and

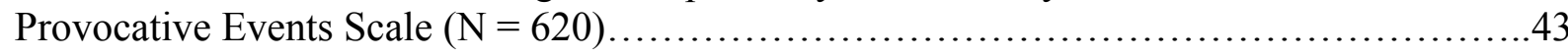

3. Factor Loadings for Confirmatory Factor Analysis of Revised Painful and Provocative Events

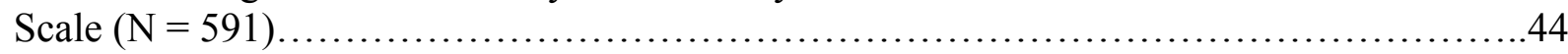

4. Means and Standard Deviations for, and Intercorrelations Between, Full Sample Variables of

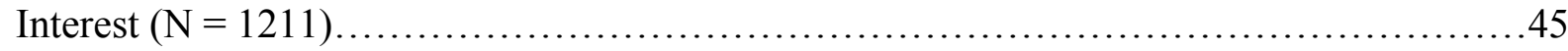

5. Hierarchical Multiple Regression Equation Predicting SBQ-R Score in a Sample of 1079 Undergraduate Cyberbullying Victims..............................................46

6. Hierarchical Multiple Regression Equation Predicting SBQ-R Score in a Subsample of 156 Undergraduate Cyberbullying Victims ........................................... 47 


\section{LIST OF FIGURES}

1. Original specified model for path analysis to test IPTS by predicting SBQ-R total score from

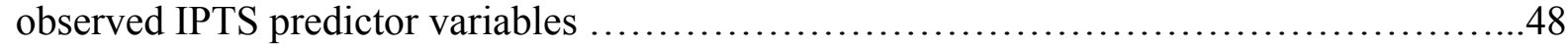

2. Scree plot for exploratory factor analysis of revised painful and provocative events scale....49

3. Confirmatory factor analysis for painful and provocative events scale...................50

4. Final specified path analysis of IPTS variables predicting SBQ-R score....................51 


\section{LIST OF APPENDICES}

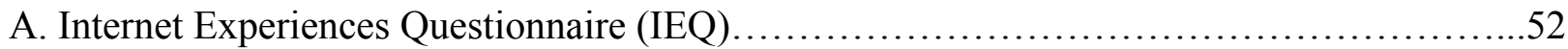

B. Painful and Provocative Events Scale (PPES) and Additional Items......................60 
Examining the Painful and Provocative Events Scale and Testing the Interpersonal-Psychological Theory of Suicidal Behavior in Undergraduates and Cyberbullying Victims

\section{Suicide}

Suicide is the phenomenon of intentional, self-inflicted death. According to recent U.S. Center for Disease Control and Prevention (CDC) statistics, 36,025 Americans completed suicide in 2008, making suicide the tenth most common form of death in the United States (2011). The impact of suicide only begins with the death totals. In addition to deaths by suicide, it is estimated that one million adults in the U.S. attempt suicide annually, while 2.2 million make suicide plans, and 8.3 million people, $3.7 \%$ of the U.S. population, have thoughts of suicide each year (CDC, 2011). The individual experiencing thoughts of suicide or attempting is not the only one affected. Family members, friends, loved ones, coworkers, and community members may all be affected by suicide, suicide attempts, and suicide thoughts. Clark and Goldney (2000) suggest that each suicide results in the suffering of six additional individuals. Suicide affects people across the lifespan, and while older adults are at a disproportionate risk for death by suicide, other high-risk groups such as adolescents, combat veterans, and victims of cyberbullying have been identified (American Association of Suicidology (AAS), 2009; AAS, 2011; Anestis, Bryan, Cornette, \& Joiner, 2009; and Hinduja \& Patchin, 2010)

\section{The Interpersonal-Psychological Theory of Suicidal Behavior}

The completion of suicide is a multi-faceted process. In research, relationships between suicidal behavior and a variety of biological, psychological, and social risk factors have been demonstrated (Van Orden, Witte, Gordon, Bender, \& Joiner, 2010). The InterpersonalPsychological Theory of Suicide (IPTS), proposed by Joiner (2005) attempts to explain suicide as the interaction of three main components: thwarted belonging, perceived burdensomeness, and 
the acquired capability for suicide. Thwarted belonging is the sense of disconnect a person may experience when interpersonal relationships are nonexistent or feel meaningless. Perceived burdensomeness is the extent to which an individual feels that his or her presence makes life more difficult for those around the individual, the sense that others would be "better off" without me around (Joiner, 2005). Together, the burdensomeness and belonging components make up the desire for death by suicide. However, desire alone does not result in suicide; a person must also be capable of the act. An individual who has acquired the capability for suicide has in some way developed a tolerance for physical pain and has come to fear death less. The rare combination of this tolerance for pain and decreased fear of death enables a select set of people who desire suicide to carry out a lethal act against the self (Van Orden et al., 2010). Bender Gordon, Bresin, and Joiner (2011) explain that individuals acquire an irreversible capability for suicide through exposure to painful and provocative events, events which result in an increased tolerance for pain and/or decreased fear of death. Some such events — physical fights, drug use, or engaging in thrill-seeking behaviors — may be tied to impulsivity, while others — seeing injuries as a medical professional or being a victim of physical or sexual abuse — are not tied to impulsivity (Bender et al., 2011; Lindeman et al., 2006; Witte et al., 2008). Additionally, the IPTS proposes that the risk of suicide is greatest in individuals who both desire suicide and have the capability to act on that desire.

Instruments developed to test the IPTS. Though existing instruments assessing constructs similar to those making up the IPTS have been used in research, Joiner and colleagues have developed several instruments to more specifically test the Interpersonal-Psychological Theory of Suicide. The Interpersonal Needs Questionnaire (INQ-12) is a 12-item self-report measure that asks questions relating to perceived burdensomeness and thwarted belonging (Van 
Orden, Witte, Bender, Gordon, \& Joiner, 2008a). Seven INQ-12 questions pertain to burdensomeness, while five questions address thwarted belonging.

The Acquired Capability for Suicide Scale (ACSS) is a 20-item self-report questionnaire that attempts to measure the extent to which individuals possess a decreased fear of death and an increased pain tolerance (Van Orden et al., 2008a). Van Orden et al. (2010) hypothesized a twofactor structure for the ACSS with items addressing either decreased fear of death or an increased tolerance for pain. An exploratory factor analysis conducted by Smith, WolfordClevenger, Mandracchia, and Jahn (2013), found three meaningful factors that make up the ACSS: General fearlessness and perceived pain tolerance, fearlessness of death, and spectator enjoyment of violence.

In order to address how individuals acquire the capability for suicide, Van Orden et al. (2008a) also developed the Painful and Provocative Events Scale (PPES), a self-report measure of varying lengths that measures experiences that are hypothesized to contribute to increased pain tolerance and a decreased fear of death. Bender et al. (2011) found that PPES score mediates the relationship between impulsivity and suicidality, such that greater impulsivity leads to the experiencing of more painful and provocative events which, in turn facilitate the acquisition of the capability for suicide. Furthermore, Bender, Anestis, Anestis, Gordon, and Joiner (2012) found that individuals high in distress tolerance are more likely to report acquired capability for suicide when they also are sensation seekers - those likely to take part in impulsive, chosen, painful and provocative events. While versions of the INQ, ACSS, and PPES are frequently used in tests of the Interpersonal-Psychological Theory of Suicide, they are relatively new measures that can be improved with further research. One focus of the current 
study was to examine the role of painful and provocative events in suicidal behavior and to explore revisions to improve the painful and provocative events scale.

Changing the painful and provocative events scale (PPES). The Interpersonal Psychological Theory of Suicide posits that painful and provocative events are the experiences through which individuals directly acquire a cumulative capability to enact suicidal behavior (Van Orden, et al., 2010). Strong correlations between measures of painful and provocative events (PPES) and acquired capability for suicide (ACSS) would support this hypothesis. Bender et al. (2011) found a moderate correlation between a combination of the Painful and Provocative Events Scale (PPES) and Impulsive Behavior Scale (IBS; Rossotto, Yager, \& Rorty, 1998) and the 20-item Acquired Capability for Suicide Scale (ACSS), $r=.42, p<.001$. Van Orden et al. (2008a) also found a weak to moderate, but significant correlation $(r=.29, p<.01)$ between the combined PPES and IBS measure and a 5-item version of the ACSS. The correlations among the PPES and the ACSS are significant, but perhaps not as large as expected for two closely related constructs.

One potential reason for the weaker than expected correlations is that the items on the Painful and Provocative Events Scale (PPES) appear to be weighted heavily toward proactive, chosen events such as skydiving and getting a tattoo. Such willfully chosen painful and provocative events are likely to correlate strongly with impulsivity and lead to an acquired capability for suicide. However, previous versions of the PPES seem to largely neglect the established possibility that an individual can acquire the capability for suicide in a more passive manner, through events that are not chosen, but rather imposed on the individual. Examples of such reactive events may include experiencing the death or suicide attempt of a loved one or being the victim of a disease or of a violent crime. Unlike the proactive events, an individual 
does not choose to experience the death of a loved one or to be a victim of a disease or a violent crime. Experiencing any of these events was not expected to correlate highly with impulsivity, nevertheless such an experience may cause an individual to fear death less or tolerate pain more.

One goal of the present study was to better understand the relations between the experiencing of proactive and reactive painful and provocative events and the acquired capability for suicide. In doing so, it was hypothesized that the revised PPES would more accurately assess the variety of experiences that may lead to an acquired capability for suicide and more strongly correlate with the ACSS.

\section{Tests of the Interpersonal-Psychological Theory of Suicidal Behavior}

Since the publication of Joiner's seminal work on the Interpersonal-Psychological Theory of Suicide, Why People Die by Suicide (2005), researchers have tested the theory and its components with various populations including undergraduates, clinical populations, young adults, and military samples (Anestis, Bryan, Cornette, \& Joiner, 2009) using various measures of each component.

Undergraduates, young adults, and clinical populations. In 2007, suicide was the third leading cause of death for adolescents 10-24 years of age (AAS, 2011). The InterpersonalPsychological Theory has been tested in undergraduate and clinical samples using instruments developed to capture the three main components of the model (Van Orden et al., 2008a). In the first study, Van Orden et al. (2008a) focused on the components of burdensomeness and thwarted belonging. Van Orden et al. (2008a) used the Interpersonal Needs Questionnaire to predict suicidal ideation as measured by the Beck Scale for Suicidal Ideation (BSS; Beck \& Steer, 1991) in a sample of 309 undergraduate students. Van Orden et al. (2008a) found that a model including age, gender, Beck Depression Inventory (BDI; Beck, Ward, Mendelson, Mock, 
\& Erbaugh, 1961) score accounted for $17 \%$ of the variance in suicidal ideation. Adding the main effects of burdensomeness and failed belonging, and the interaction between burdensomeness and failed belonging as measured by the INQ accounted for an additional 13\% of the variance in suicidal ideation. A follow-up study (Van Orden et al., 2008b) of 309 undergraduate students found that belonging, as measured by the INQ, mediated the relationship between academic semester and suicidal ideation as measured by the BSS.

The second study focused on the acquired capability component of the model. Van Orden et al. (2008a) administered a battery of tests, including the BSS, BDI, the Impulsive Behavior Scale (IBS; Rossotto, Yager, \& Rorty, 1998), the Acquired Capability for Suicide Scale (ACSS), and the Painful and Provocative Events Scale (PPES), to a clinical sample of 228 individuals. Van Orden et al. (2008a) noted that past suicide attempts, measured by the BSS, were predictive of an increased acquired capability for suicide (ACSS) score. Furthermore, this same study found that a model of age, gender, BDI score, BSS score, and PPES score accounted for $14 \%$ of the variance in ACSS score. Additionally, the results obtained by Van Orden et al. (2008a) indicate that more painful and provocative experiences (PPES score) significantly predicted the trait of acquired capability for suicide (ACSS score), accounting for seven percent of the variance in ACSS score alone.

In the third study, Van Orden et al. (2008a) tested all components of the model simultaneously. Van Orden et al. (2008a) again administered a battery of tests, ACSS, INQ, and BDI, to a different clinical sample of 153 outpatients. However, in this study, each participant was also evaluated for risk of suicide by a clinician. The results of this study indicated that a model of age, gender, and BDI score predicted 33 percent of the variance in clinician ratings of suicide risk. Adding ACSS score, burdensomeness measures from the INQ, and an interaction 
between ACSS score and burdensomeness on the INQ to the model accounted for an additional eight percent of the variance in clinician rating of suicide risk (Van Orden et al., 2008a).

In these studies Van Orden et al. (2008a; 2008b) reported that all three components of the IPTS predicted suicide risk in clinical populations and that the burdensomeness and thwarted belonging components predicted suicidal ideation in an undergraduate population. The acquired capability component of the model was not addressed with the undergraduate population.

Joiner et al. (2009) again tested the IPTS in two studies of young adults. The first study examined the components of thwarted belonging and perceived burdensomeness in an ethnically diverse community sample of 815 young adults aged 19-26 randomly selected from participants in a previous study. All participants endorsed sadness and/or anhedonia symptoms of major depression in a structured clinical interview.

In a structured clinical interview, participants were asked questions about "mattering", a construct described by Joiner et al. (2009) as "similar...to perceived burdensomeness." Additionally, participants were asked about their family and social support systems, a measure of belonging, and were interviewed with the Michigan Composite International Diagnostic Interview (CIDI; Kessler et al., 1994), which asked questions about suicidal ideation, major depression in the past six months, and lifetime major depression. As in Van Orden et al. (2008a), hierarchical linear regressions were used to analyze the relationship between belonging, burdensomeness, depression history, and the dependent variable, suicidal ideation (Joiner et al., 2009). The results indicated that a model consisting of lifetime and recent depression histories, mattering (burdensomeness), family/social support (belonging), and the interaction between burdensomeness and belonging accounted for 20 percent of the variance in suicidal ideation. 
Burdensomeness, belonging, and the burdensomeness-belonging interaction accounted for only three percent more variance in suicidal ideation than depression history alone.

In the second study, Joiner et al. (2009) tested all three facets of the IPTS in a clinical sample of 313 young adults referred for treatment because of a suicide attempt or severe suicidal ideation. This sample was given a variety of interview and self-report psycho-diagnostic assessments. Participants were interviewed about their psychosocial history in which history of suicide attempts, family psychiatric history, and relevant demographic factors were discussed. A history of suicide attempts was the indication that an individual had acquired the capability for suicide. Participants completed the self-report 36-item Suicide Probability Scale (SPS; Cull \& Gill, 1988). Joiner et al. (2009) state that certain items on the SPS pertain to the constructs of burdensomeness and failed belonging. As such, these items were used as measures of the burdensomeness and belonging components of the IPTS in this study. Participants completed a computerized version of the Diagnostic Interview Schedule (DIS; Blouin, Perez, \& Blouin, 1988) to determine current and past psychiatric diagnoses, and also completed the following selfreport measures: Beck Depression Inventory (BDI; Beck et al., 1961), Beck Hopelessness Scale (BHS; Beck, Weissman, Lester, \& Tressler, 1974), and the Millon Clinical Multiaxial Inventory Borderline Personality Disorder subscale (MCMI; Joiner et al., 2009; Millon, 1983).

The results of this study indicated that the three-way interaction among SPS burdensomeness questions, SPS belonging questions, and number of previous suicide attempts predicted whether an individual was referred to treatment for a suicide attempt versus suicidal ideation (Joiner et al., 2009). This study attempted to examine all three components of the IPTS in a young adult population, but did so with instruments not specifically designed to test the Interpersonal-Psychological Theory. The present study contains measures of perceived 
burdensomeness (INQ-12), thwarted belonging (INQ-12), acquired capability for suicide ACSS), painful and provocative events (PPES Revised), and suicidal behavior (SBQ-R). Such measures were used to test the Interpersonal-Psychological Theory of Suicide via a path analysis.

\section{Cyberbullying}

Additional populations have been linked to an increased risk for suicide. A meta-analysis of bullying research from the past 20 years has demonstrated that the odds of both suicidal intent $(O R=1.4-5.6)$ and suicidal behavior $(O R=1.5-5.4)$ were greater for child and adolescent victims of traditional, face-to-face bullying than for non-victims (Kim \& Leventhal, 2008). In the past decade, technology has become intertwined in our daily lives like never before. Our news, shopping, and friendships have evolved through technology, and bullying is no exception. In cyberbullying, individuals use electronic means (cell phone, computer, social media, etc.) to harass, intimidate, or otherwise bully others. While cyberbullying is common among adolescents, 6.6\%, (Smith, 2008), it is also prevalent on college campuses, $8.6 \%-10 \%$ (Kraft \& Wang, 2010; Schenk \& Fremouw, 2012) and in the adult world, 10.7\% (Jung, 2010; Privitera \& Campbell, 2009). Anecdotes of suicides resulting from cyberbullying have been frequent headlines in the news over the past few years. In 2006 a 13-year old girl hanged herself after being bullied online by a fake love interest. After her death it was discovered that the love interest was actually adult woman masquerading as a teenage boy to intimidate one of her daughter's former friends (ABC News, 2007). In 2010, an 18-year old Rutgers freshman completed suicide by jumping from a bridge after his romantic encounter with another man was streamed online without his consent (Schwartz, 2010).

These examples represent some of the most publicized media accounts of cyberbullying and suicide. In the academic world, research is confirming what the popular press has been 
reporting: cyberbullying is tied to suicide (Hinduja \& Patchin, 2010; Schenk \& Fremouw, 2012). Hinduja and Patchin (2010) found that victims of cyberbullying experience more suicidal ideation and are nearly twice as likely to have attempted suicide as non-victims. In one study, Schenk \& Fremouw (2012) found that 5.7\% of cyberbullying victims reported attempting suicide. Cyberbullying victims are an emerging high risk population for suicide. As such, determining the nature of the relationship between cyberbullying victimization and suicide is becoming increasingly important.

\section{Purposes}

The primary goal of the present study was to examine the factor structure and psychometric properties of the Painful and Provocative Events Scale (PPES) through factor and correlational analyses, while including additional items to revise and refine the measure.

Secondly, the study examined whether the components of the Interpersonal-Psychological Theory of Suicide adequately explain suicide-related behaviors in a) a general undergraduate sample and b) a cyberbullying victim subsample of undergraduate students. Finally, the present study tested the fit of a model of observed measures of painful and provocative events, acquired capability for suicide, perceived burdensomeness, and thwarted belonging that predict an observed measure of suicide-related behaviors.

1. The present study examined the psychometric properties of the previously unexamined Painful and Provocative Events Scale (PPES) and tested additional items to improve the content validity of the scale. Factor and correlational analyses were conducted to test and potentially improve the reliability and validity of the measure.

2. The second goal of the current study was to examine the ability of the IPTS to explain suicide-related behaviors in 1) a general undergraduate sample and 2) in a subsample of 
undergraduate cyberbullying victims. Specifically, do scores on the ACSS and INQ-12 predict suicide-related behavior as measured by the SBQ-R (Osman et al., 2001) in an undergraduate sample and a subset of that sample that endorses cyberbully victimization? It was hypothesized that ACSS scores, INQ-12 scores, and the interaction of INQ and ACSS scores would significantly predict SBQ-R scores of suicide-related behavior in both the undergraduate sample and the subsample of cyberbullying victims. The relative strength of the IPTS model for the two samples was be compared based on the percentage of variance accounted for by the INQ-12, ACSS, and ACSS-INQ-12 interaction.

3. The final goal of the present study was to test the theoretical model of the InterpersonalPsychological Theory of Suicide using a path analysis of observed measures (INQ-12, PPES-Revised, ACSS, BIS) to predict suicide-related behaviors (SBQ-R).

\section{Method}

\section{Design}

Exploratory and confirmatory factor analyses were conducted to examine the factor structure of the revised painful and provocative events scale with additional proactive and reactive items. Correlational analyses were conducted with measures of trait impulsivity, fearlessness, depression, suicide-related behavior, and acquired capability for suicide to assess the convergent and discriminant validity of the resulting proactive and reactive subscales.

Hierarchical multiple regression analyses were conducted to examine the relationships among several predictor variables and the dependent variable, SBQ-R score, in an undergraduate sample and a cyberbullying subsample. The predictor variables of greatest interest were those relating to the three components of the IPTS: the Interpersonal Needs Questionnaire-12 (INQ12), the Acquired Capability for Suicide Scale (ACSS), and the interaction between the INQ-12 
and the ACSS. Additional predictor variables included the demographic variables of age, gender, and ethnicity, as well as scores on the Beck Depression Inventory-II (BDI-II), Barratt Impulsiveness Scale (BIS), Psychopathic Personality Inventory-Revised fearless dominance scale (PPI-R), and the Painful and Provocative Events Scale (PPES). An observed variable path analysis was conducted to examine the fit of a model of the IPTS including the new painful and provocative events factors.

\section{Participants}

An initial sample of 1436 undergraduate students completed a battery of self-report measures via SONA, a university system for online survey research. Three exclusion criteria were used to eliminate participants who did not carefully attend to the survey. Fifty-two respondents were not included in analyses after completing less than $50 \%$ of the survey. An additional 27 respondents ( $2 \%$ of the sample) were eliminated from analyses after completing the survey in less than 13 minutes, half the median response time. Finally, 145 respondents were excluded from analyses for infrequent responding after scoring a four or higher on the Zuckerman-Kuhlman Infrequency Scale. The final sample contained 1211 participants, though missing data on some measures resulted in listwise deletion and reduced sample sizes in analyses. With regard to suicidal behavior, 38 participants (3.1\%) acknowledged a past suicide attempt, while an additional $110(9.1 \%)$ acknowledged suicidal ideation with a plan to die. Demographic information about the full sample can be found in Table 1.

All participants were students in various undergraduate courses who voluntarily chose to complete the study as one option for extra credit. This study was approved by the Institutional Review Board of West Virginia University. One-hundred and seventy-three participants (14.3\%) were identified as victims of cyberbullying using the dual criteria identified by Schenk \& 
Fremouw (2012). To be classified a cyberbullying victim, participants must have answered 'yes' to a direct question about cyberbullying victimization (i.e. 'Have you been a victim of cyberbullying) and endorsed the experiencing of at least four instances of cyberbullying behavior (Schenk \& Fremouw, 2012). Table 1 contains demographic information about the cyberbullying victim subsample.

\section{Measures}

Demographic questionnaire. Participants completed a survey of demographic information regarding age, university class status (e.g. freshman, junior, etc.), ethnicity, sex, marital status, grade point average, history of mental health services, and internet usage (Appendix A).

Internet experiences questionnaire (IEQ). The IEQ (Schenk \& Fremouw, 2012;

Appendix A), a 47-item questionnaire examining victimization, perpetration, impact, and coping relating to both traditional and cyberbullying, was used to identify the subsample of cyberbullying victims. The IEQ has various response formats including free response, single response multiple choice, and multiple response multiple choice options. The IEQ was developed using items from a multitude of previous studies, and has been used successfully to discriminate between victims and non-victims of cyberbullying (Schenk \& Fremouw, 2012). Psychometric information on the IEQ has not been published.

Suicidal behaviors questionnaire revised (SBQ-R). The Suicidal Behaviors Questionnaire-Revised (Osman et al., 2001) was used to provide a single measure of suiciderelated behavior as the dependent variable in the hierarchical regressions and path analysis. The SBQ-R is a frequently used four-item, self-report measure of four facets of suicidality: lifetime suicidality and attempts, frequency of suicidal ideation in the past year, lifetime threat of suicide, 
and risk of future suicide attempt. Each item is phrased as a question, and participants are asked to choose one of multiple response options for the item. Each response has an assigned point value. Point values of the four items are totaled, providing a total SBQ-R score. Osman et al. (2001) have found estimates of internal consistency ranging from adequate to moderately high ( $\alpha$ $=.76-.88$ ). Scores on the SBQ-R were found to discriminate between suicidal and non-suicidal participants (Osman et al., 2001). Internal consistency for the SBQ-R in the current sample was good, .82.

Interpersonal needs questionnaire (INQ-12). In the present study the INQ-12 served as a predictor variable representing the burdensomeness and belonging components of the IPTS in the hierarchical regressions. The INQ-12 is a 12-item self-report measure of the InterpersonalPsychological Theory of Suicide (IPTS) developed Van Orden et al. (2008a). The INQ-12 is divided into two subscales measuring the IPTS constructs of perceived burdensomeness and failed belonging. Participants respond to seven burdensomeness items and five belonging items on a seven point Likert-type scale ranging from "Not at all true for me" to "Very true for me" (Van Orden et al., 2008a). Higher scores on the burdensomeness and failed belonging subscales reflect higher degrees of those constructs. Freedenthal, Lamis, Osman, Kahlo, and Gutierrez (2011) found a coefficient alpha estimate of internal consistency of .93 for the combined scale, .93 for the thwarted belonging subscale, and .92 for the perceived burdensomeness subscale. For the path analysis in the present study, the INQ-12 was divided into burdensomeness and thwarted belonging variables as specified by Van Orden et al. (2008a). In the current study, evidence for good internal consistency was found for the burdensomeness subscale $(\alpha=.79)$, for the thwarted belonging subscale $(\alpha=.84)$, and for the combined scale $(\alpha=.90)$. 
Evidence for construct validity has been demonstrated through moderate positive correlations with related constructs, such as depressive symptoms and hopelessness, and moderate negative correlations with measures of social support and reasons for living (Freedenthal et al., 2011). Additional evidence of construct validity has been demonstrated through weak and non-significant correlations with the ACSS, which measures a construct hypothesized to be weakly associated with constructs measured by the INQ-12 (Freedenthal et al., 2011).

Acquired capability for suicide scale (ACSS). The ACSS served as a predictor variable representing the acquired capability component of the IPTS in the hierarchical regressions. The three meaningful factors obtained by Smith et al. (2013) were used as observed variables in the path analysis. The ACSS (Bender et al., 2011; Van Orden et al., 2008a) is a 20-item self-report measure examining the extent to which participants endorse items relating to a decreased fear of death and an increased tolerance for pain (e.g. I can tolerate a lot more pain than most people.). In some studies a five-item version (Van Orden et al., 2008a) or a six-item version (Bender et al., 2011) of the ACSS has been used. Participants rate how well each item describes his or herself on a five-point Likert-type scale ranging from zero (not at all like me) to four (very much like me), with no anchor labels for points one, two and three (Bender et al. 2011; Van Orden et al., 2008a). The values of the responses are summed to achieve a total ACSS score. Evidence for convergent validity between the five, six, or 20-item versions of the ACSS and related constructs has been demonstrated through a strong correlation with a Beck Scale for Suicidal Ideation (Beck \& Steer, 1991) question asking about "courage and ability to commit suicide" $(r=.79, p=$ .007), moderate correlation with clinicians' ratings of suicide risk $(r=.43, p<.01)$, a behavioral measure of pain tolerance $(r=.42, p<.001)$ and sensation seeking $(r=.50, p<.001)$, and a 
weak correlation with past suicide attempts $(r=.17, p<.05$; Bender et al., 2011; Van Orden et al., 2008a).

Studies of the five-item ACSS have also demonstrated discriminant validity. Van Orden et al. (2008a) found no relationship between the ACSS and the Beck Depression Inventory ( $r=$ $.01, p=n . s$.$) or the perceived burdensomeness items from the Interpersonal Needs Questionnaire$ $(r=.09, p=n . s$.$) . Additionally, the ACSS has been found to correlate negatively with the fear of$ suicide subscale of Linehan's 1983 Reasons for Living Inventory, $r=-.48, p<.0001$ (Linehan, Goodstein, Nielsen, \& Chiles, 1983; Van Orden et al., 2008). Internal consistency of the 20-item ACSS in the current sample was good $(\alpha=.82)$. Internal consistency was .64 for the general fearlessness and perceived pain tolerance factor, .71 for the fearless of death factor, and .77 for the spectator enjoyment of violence factor.

Painful and provocative events scale (PPES) and additional items. The present study sought to improve the PPES through exploratory and confirmatory factor analytic procedures (Appendix B). A revised painful and provocative events scale was developed during the course of the present study. A proactive and a reactive factor were used in the path analyses. The painful and provocative events scale (PPES) is a 24-item measure, assessing the frequency of an individual's experiencing events hypothesized to lead to an increased tolerance for pain or a reduced fear of death (e.g. Have you ever been a victim of sexual abuse? Have you gone skydiving?). Participants respond to items on the PPES using a five-item Likert-type scale on which $1=$ never, $2=$ once, $3=$ on occasion, $4=$ sometimes, $5=$ regularly (Bender et al., 2011; Van Orden et al., 2008a). Various versions of the PPES have been used. Bender et al. (2011) and Van Orden et al. (2008a) used a 10-item version, while Bender et al. (2011) used an 18-item version. Additionally, the PPES has frequently been combined with the Impulsive Behavior 
Scale (IBS) - a 25-item measure asking about an individual's participation in impulsive behaviors, measured on the same five-point Likert-type scale as the PPES (Bender et al., 2011; Rossotto, Yager, \& Rorty, 1998).

Studies involving the PPES have frequently combined the IBS and the 10-item PPES into a single scale, computing measures of internal consistency and correlations with other instruments for the combined measure rather than for the PPES and IBS individually. As such, it is difficult to isolate correlations among the PPES and other measures. Only a thesis by Bender (2009) seems to examine the PPES alone, but in this study there is no indication of which version of the PPES was used (24-item, 18-item, 10-item or other). Bender (2009) found an unidentified version of the PPES to correlate with an unidentified-item version of the ACSS $(r=.43, p<$ $.001)$, indicating convergent validity. Additionally, the PPES correlated with the Barratt Impulsiveness Scale trait measure of impulsivity (BIS-11; Patton, Stanford, \& Barratt, 1995) and the Impulsive Behavior Scale (IBS), $r=.67, p<.01$ and $r=.26, p<.01$ respectively (Bender, 2009). The correlations with these impulsivity measures are also unsurprising, as impulsivity leads to impulsive behaviors which are theorized to include a great number of events that can increase pain tolerance and decrease fear of death. High scores on the PPES also correlated with increased pain tolerance and pain threshold as measured by a pressure algometer, $r=.41, p<$ $.01, r=.19, p<.05$ respectively (Bender, 2009). Discriminant validity of the PPES alone has not been reported. Bender (2009) found evidence for internal consistency with the PPES (Cronbach's $\alpha=.71$ ). The variability of items used in different studies makes it difficult to draw overall conclusions about the scale. Thirty items about experiences hypothesized to lead to an increased tolerance for pain and a decreased fear of death were added to the item pool administered to the sample. The same 5-point Likert-type scale was used for these items. In the 
present study, factor analyses with examinations of individual item loadings were conducted to attempt improve the scale.

Development of 30 additional items. Thirty additional items were added to the item pool of the PPES. Each added item was hypothesized to result in an increased tolerance for pain or a decreased fear of death. Some items, like cyberbullying victimization (Schenk \& Fremouw, 2012) were based on previous research findings. Other items, like trapping animals were generated through discussions with experts in suicide risk-assessment. Finally, additional items like caving/spelunking were added to the item pool based on their similarity to the original 24 PPES items. The 30 additional items (Appendix B) were administered after the 24 original PPES items. All 54 items were entered into the exploratory factor analysis.

Barratt impulsiveness scale (BIS). In the present study a modified version ${ }^{1}$ of the BIS was used as potential evidence of discriminant validity for the revised PPES, and as a predictor in the hierarchical regression analyses. The modified Barratt Impulsiveness Scale is a 23-item, self-report measure that examines trait impulsivity (Patton et al., 1995). Respondents rate the extent to which each item accurately describes his or her behavior on a four-point Likert-type scale ranging from "rarely/never" to almost "always/always." Higher scores on the BIS indicate higher levels of trait impulsivity. The BIS can be subdivided into three second-order factors:

\footnotetext{
${ }^{1}$ The author intended to use the BIS-11. During data collection, it was discovered that the BIS-11A — an unfinished test version of the BIS-11—was inadvertently used. Additionally, one item from the BIS-11A—“I change jobs"was unintentionally omitted from survey administration. BIS-11A to BIS-11 conversion procedures as detailed in Lijffijt (2012) were used to remove five items that did not make the BIS-11. BIS variables used in the present study include: a 23-item total BIS score, a 5-item cognitive factor score, and 10-item non-planning factor score, and an 8item motor factor score that omits the "change jobs" item. Each score was calculated by summing the items, and neither total nor factor scores were prorated.
} 
Cognitive, motor, and non-planning impulsiveness. These three second order factors were entered into the path analysis in the present study.

Patton, Stanford, and Barratt (1995) found evidence for good internal consistency in the BIS in various populations including undergraduates $(\alpha=.79)$, substance abuse patients $(\alpha=$ .79), general psychiatric patients $(\alpha=.83)$, and prison inmates $(\alpha=.80)$. In the current sample, internal consistency was good $(\alpha=.83)$ for the BIS total score, acceptable for the non-planning factor $(\alpha=.74)$, and questionable for the attentional $(\alpha=.60)$ and motor impulsiveness factors $(\alpha$ $=.63)$.

Beck depression inventory (BDI-II). The BDI-II was used as potential evidence of discriminant validity in the development of a revised painful and provocative events scale and as a predictor in the hierarchical regression analyses. The BDI-II (Beck, Steer, \& Brown, 1996) is a commonly used 21-item self-report instrument measuring depressive symptomatology. Participants answer each item relating to a different depressive symptom with one of four possible answers. Each answer is assigned a point total ranging from zero to three. Summing the point totals of each item yields a total BDI-II score ranging from 0-63. Higher scores indicate greater depressive symptomatology (Beck, Steer, and Brown, 1996). The BDI has been found to correlate strongly with measures of self-report anxiety and depression (Storch, Roberti, \& Roth, 2004). Sprinkle et al. (2002) found the BDI-II to have test-retest reliability of $r=.96$. Evidence for good internal consistency of the BDI-II was found with the current sample (Cronbach's $\alpha=.91)$.

\section{Psychopathic personality inventory revised (PPI-R) fearless dominance subscale.}

The PPI-R (Lilienfeld \& Widows, 2005) was used as potential evidence of convergent validity in the development of a revised Painful and Provocative Events Scale and as a predictor variable in 
the hierarchical regression analyses. The PPI-R is a measure of psychopathy and the specific traits, identified by subscales, which make up psychopathy. The fearless dominance subscale of the PPI-R contains 14 self-report items that are hypothesized to be related to the construct of fearlessness (e.g. 'I am a daredevil'). Participants rate the extent to which each item's statement describes his or herself on a four-point scale ranging from false or mostly false to mostly true or true. Test-retest reliability $(r=.94)$ has been demonstrated on the PPI-R fearless dominance scale in a community/college sample (Lilienfeld \& Widows, 2005). Internal consistency for the current sample was good $(\alpha=.87)$.

\section{Zuckerman-Kuhlman personality questionnaire infrequency scale and Crowne-}

Marlow social desirability scale. In the present study, the Zuckerman-Kuhlman items were scored to test for infrequency of responding in order to eliminate inattentive participants. The Zuckerman-Kuhlman Personality Questionnaire (Zuckerman, 2002) contains a 10-item infrequency scale used to validate participant responding. The scale consists of socially desirable items phrased in such absolute language that the items are difficult to honestly endorse (e.g. 'I have always told the truth'). Participants respond "true" or "false" to each item. "True" responses are scored as zero, while "false" responses are scored as one. Scores of four or greater indicate that participants may have been inattentive or answering in socially desirable ways. In order to conceal the nature of the questions, ten items from the Crowne-Marlowe Social Desirability Scale (Crowne \& Marlowe, 1960) were used as distractors.

\section{Procedures}

A battery of self-report measures were administered to 1436 participants through the Sona system at West Virginia University. Sona is an online program that enables the administration and collection of survey research. Participants enrolled in undergraduate 
psychology courses were able to earn extra credit in exchange for participation in the current study. Before accessing the study, all participants were required to acknowledge their voluntary consent, by selecting the "I Agree" option. Because the anonymous study asked questions about suicide, participants were also required to consent to reading a list of mental health resources before being directed to the web-based survey. Next, participants anonymously completed a battery of self-report measures including a demographic questionnaire, the Suicidal Behaviors Questionnaire-Revised, Internet Experiences Questionnaire, Interpersonal Needs Questionnaire12, Acquired Capability for Suicide Scale, Painful and Provocative Events Scale, Beck Depression Inventory-II, Barratt Impulsivity Scale, the Psychopathic Personality InventoryRevised fearless dominance scale, and the Zuckerman-Kuhlman infrequency scale. At all times during the survey, participants were free to refuse to answer any question and also to withdraw his or her participation. Following the study, participants were debriefed and provided with information about local psychological resources.

\section{Data Analysis}

Power analyses. A priori power analyses were conducted for each proposed statistical test to determine the number of participants required to observe a moderate effect. The statistical program $\mathrm{G}^{*}$ Power was used to estimate that a sample of 76 is needed to observe an effect size of .2 with .90 power in a hierarchical regression with six predictors entered in the first step and three predictors entered in the second step ( $\mathrm{G}^{*}$ Power). It was estimated that obtaining a sample of 76 cyberbullying victims at a base rate of $8 \%$ (Schenk \& Fremouw, 2012) required a sample size approaching 1000 participants.

With regard to the exploratory factor analysis, MacCallum, Widaman, Zhang, and Hong (1997) recommend using the estimated number of factors and communalities among the 
variables to estimate a priori effect size. However, when communalities cannot be determined, MacCallum et al. (1997) recommend obtaining as large a sample as possible. Furthermore, under the worst conditions with the worst communalities, they recommend using over 500 participants (MacCallum et al., 1997). The sample size required for the factor analysis was much greater than the sample size required to perform a hierarchical regression, therefore the total sample size needed to have adequate power was based on the criteria laid out in MacCallum et al. (1997). In the present study a sample size of 900-1000 total undergraduates and 70-80 victims of cyberbullying was feasible and desirable for adequate power.

Post-collection data analyses. The sample was randomly divided into two groups, each containing approximately 50 percent of total participants. An exploratory factor analysis was conducted with half of the sample to examine the factor structure of the pool of 54 PPES items, composed of 24 original items plus 30 newly generated items. Principal axis factoring and promax rotations were used as the extraction and rotation methods (Furr, 2011). The decision to retain two factors was made through examination of the scree plot. When examining the pattern matrix, a cut-off of .3 was used, such that items loading less than .3 on either factor and items loading more than .3 on both factors were dropped (Floyd \& Widaman, 1995). The same factor structure obtained in the exploratory factor analysis was modeled in a confirmatory factor analysis using the statistical program Amos. The specified model was adjusted using modification indices to allow covariance between error terms within the same factor. Model fit was then assessed for adequacy. Correlational analyses using data from the full sample were conducted to examine the validity of the resulting factors. Pearson product-moment correlations with the ACSS total scale and subscales were used to address criterion-related validity, while Pearson correlations with the INQ-12 total score and subscales, PPI-R fearless dominance 
subscale, BIS total score and subscales, and SBQ-R were used to address discriminant and convergent validity.

Hierarchical regression analyses were conducted to examine the ability of the three facets of the IPTS, as measured by ACSS and INQ-12 scores, to account for variance in SBQ-R score in an undergraduate population, and in a subsample of undergraduate cyberbullying victims. In each hierarchical regression, log transformed SBQ-R score served as the dependent variable. Age, gender, BDI-II, BIS, and PPI-R fearless dominance scale were entered in step one, while the centered INQ-12 and centered ACSS were entered as predictors in step two. In step three, the centered INQ-12-ACSS interaction was entered into the equation. Means were imputed for missing items if the participant had completed 70 percent or more of the measure containing the missing item (e.g. ACSS).

A theory-driven path analysis was conducted to test the fit of the IPTS while incorporating the resulting PPES factors. In the model, impulsiveness (BIS), revised painful and provocative events proactive and reactive factors, acquired capability factors as identified by Smith et al. (2013), and INQ-12 divided into burdensomeness and failed belonging were all used as observed variables to predict another observed variable, suicide-related behavior (SBQ-R total score). A hypothesized model (Figure 1) based on the Interpersonal-Psychological Theory of Suicidal Behavior was specified. This model was tested for fit. If a model was found to have poor fit, single, conceptually-driven, modifications were made and tested in an iterative fashion until a model with adequate fit was obtained. First, observed variables that did not significantly contribute to the model were removed. Then, conceptually-relevant alternate paths between observed variables were considered. Finally, an examination of modification indices resulted in the addition of conceptually-relevant covariances specified between observed variables, resulting 
in a revised path model. Mediating effects were examined using the statistical program, PROCESS (Hayes, 2013).

\section{Results}

All analyses were conducted using PASW Statistics 18, IBM SPSS Amos 21, and Andrew Hayes’ PROCESS.

\section{Factor Analysis}

The 1211-participant sample was randomly divided into two groups containing approximately $50 \%$ of the total sample. Independent samples t-tests revealed no significant differences in age, gender, ethnicity, cyberbullying victimization, past suicide attempts, or SBQR total score between the groups.

Exploratory. A principal axis factoring exploratory factor analysis with promax rotation was conducted with 620 participants. Examination of the scree plot (Figure 2) indicated that either a two or three-factor model was most appropriate. In examining the item-factor loadings, two conceptually-meaningfuly factors emerged, while the third factor was composed of three highly-intercorrelated chronic pain items. At this point, a 2-factor structure was determined to be most appropriate. Seventeen items were retained on a two factor model, of which eleven items loaded on the proactive factor and six items loaded on the reactive factor (Table 2). Internal consistency, Cronbach's $\alpha$, was. 76 for the proactive factor and .57 for the reactive factor.

Confirmatory. A confirmatory factor analysis was conducted with the other half of the sample in order to replicate the exploratory factor analysis $(\mathrm{N}=591)$. The initial CFA, without using modification indices, indicated poor fit, $\chi^{2}=706.65(119, \mathrm{~N}=590), \mathrm{p}=.000$ (Figure 4). Additional indicies also indicated poor model fit: $\mathrm{CMIN} / \mathrm{DF}=5.94, \mathrm{CFI}=.66, \mathrm{RMSEA}=.091$, 90\% CI [.085-.098], SRMR $=.086$. Despite a significant chi-squared $\left(\chi^{2}=185.28,107, \mathrm{~N}=\right.$ 
$590, p=.000)$, the confirmatory factor analysis after modification indices indicated that the specified two-factor model was a good fit with the replication sample as well, CMIN/DF $=1.73$, $\mathrm{CFI}=.955, \mathrm{RMSEA}=.035,90 \% \mathrm{CI}[.027-.044], \mathrm{SRMR}=.047$. Figure 3 contains the specified model used in the confirmatory factor analysis, and Table 3 presents the factor loadings. Internal consistency, Cronbach's $\alpha$, was .73 for the proactive factor and .60 for the reactive factor.

Moderate to strong correlations were found between the proactive factor and the total ACSS, its factors, and the PPI-R fearless dominance scale. The proactive factor was weakly correlated or uncorrelated with the INQ-12 and its subscales, the BIS and its subscales, the BDIII, and the SBQ-R. The reactive factor was moderately correlated with the SBQ-R and the BDIII. Weak to moderate correlations were found between the proactive factor and the INQ-12 and its subscales and the BIS and its subscales. The reactive factor was uncorrelated or weakly correlated with the ACSS and its subscales and the PPI-R fearless dominance scale. Intercorrelations among all variables of interest for the full sample can be found in Table 4.

\section{Tests of the Interpersonal-Psychological Theory of Suicidal Behavior}

A hierarchical regression was conducted on the full undergraduate sample of 1079 participants (132 were deleted from analyses listwise ${ }^{2}$ ). Including the InterpersonalPsychological Theory of Suicidal Behavior variables-INQ-12 $(\mathrm{M}=22.15, \mathrm{SD}=11.32)$ and $\operatorname{ACSS}(\mathrm{M}=35.09, \mathrm{SD}=9.94)$ — significantly accounted for 5.9\% more variance in SBQ-R score $(\mathrm{M}=4.57, \mathrm{SD}=2.44)$ than demographic variables, BDI-II $(\mathrm{M}=9.10, \mathrm{SD}=8.55), \mathrm{BIS}(\mathrm{M}=$ 63.75, $\mathrm{SD}=8.17)$, and PPI-R fearless dominance $(\mathrm{M}=31.96, \mathrm{SD}=8.61), \mathrm{F}(8,1070)=68.92$, $\mathrm{p}<.000$ (Table 5). The INQ-12-ACSS interaction did not account for significantly more

\footnotetext{
${ }^{2}$ Participants deleted listwise did not significantly differ from participants retained for analyses on any of the variables entered in the hierarchical regression analyses.
} 
variance in SBQ-R score than the INQ-12 or ACSS variables entered separately, $\mathrm{t}(1070)=1.43$, $\mathrm{p}=.152$

The same hierarchical regression was conducted with a subsample of 156 cyberbullying victims (14 participants were deleted from analyses listwise $\left.{ }^{2}\right)$. Including the InterpersonalPsychological Theory of Suicidal Behavior variables-INQ-12 (M=25.39, SD = 13.13) and $\operatorname{ACSS}(\mathrm{M}=33.68, \mathrm{SD}=9.37)$ — significantly accounted for 5.5\% more variance in SBQ-R score $(\mathrm{M}=5.48, \mathrm{SD}=2.96)$ than demographic variables, $\mathrm{BDI}-\mathrm{II}(\mathrm{M}=12.58, \mathrm{SD}=9.00), \mathrm{BIS}(\mathrm{M}=$ 65.19, $\mathrm{SD}=7.54)$, and PPI-R fearless dominance $(\mathrm{M}=31.75, \mathrm{SD}=8.57), \mathrm{F}(8,155)=6.88 \mathrm{p}<$ .000 (Table 6). The INQ-12-ACSS interaction did not account for significantly more variance in $\log$ transformed SBQ-R score, $\mathrm{t}(147)=0.46, \mathrm{p}=.643$.

An observed variable path analysis was conducted to test the IPTS using the 1209 participants (Figure 1), two participants were excluded listwise ${ }^{3}$ from the analyses. The initial model demonstrated poor fit, $\chi^{2}=2029.09(33, \mathrm{~N}=1209), \mathrm{p}=.000$. Additional indicies also indicated poor model fit: $\mathrm{CMIN} / \mathrm{DF}=61.49, \mathrm{CFI}=.38, \mathrm{RMSEA}=.224,90 \% \mathrm{CI}[.216-.232]$, $\mathrm{SRMR}=.178$. The final model, obtained after iterative modifications, demonstrated good fit, $\chi^{2}$ $=1.83(3, \mathrm{~N}=1209), \mathrm{p}=.609$ (Figure 4). Additional indicies also indicated good model fit: $\mathrm{CMIN} / \mathrm{DF}=.61, \mathrm{CFI}=1.00, \mathrm{RMSEA}=.000,90 \% \mathrm{CI}[.000-.040], \mathrm{SRMR}=.009 . \mathrm{PPES}$ proactive, PPES reactive, INQ-12 burdensomeness, and ACSS fearlessness of death variables accounted for $37 \%$ of variance in SBQ-R total score. Two indirect, mediation pathways were significant as evidenced by the $95 \%$ confidence intervals associated with the bootstrapped estimates (10,000 samples) that did not contain zero. The indirect effect of reactive PPES on SBQ-R total score through INQ-12 burdensomeness items was significant $(b=.118, \mathrm{SE}=.018$, ${ }^{3}$ Participants deleted listwise did not significantly differ from participants retained for analyses on any of
the variables entered in the path analysis. 
95\% CI: .086-.159). The indirect effect of reactive PPES on SBQ-R total score through ACSS fearlessness of death factor was also significant $(b=.006, \mathrm{SE}=.004,95 \% \mathrm{CI}$ : .001-.016).

\section{Discussion}

To our knowledge, the present study is the first to examine the factor structure of the painful and provocative events scale or to examine the full IPTS in an undergraduate sample or cyberbullying victim sample using IPTS measures.

\section{Factor Analyses}

We then conducted exploratory and confirmatory factor analyses on different samples to identify and confirm a factor structure, and correlated the resulting factors with measures of theoretically related and unrelated constructs. The exploratory factor analysis yielded two factors: an 11-item, proactive factor and a 6-item, reactive factor. This factor structure was replicated with a different sample in the confirmatory factor analysis. All fit indices other than a significant $\chi^{2}$, indicated good fit. Schumacker and Lomax (2004) state that the $\chi^{2}$ criterion "can lead to erroneous conclusions" regarding model fit, because "as sample size increases (generally above 200), the $\chi^{2}$ statistic has a tendency to indicate a significant probability level” (p. 92). Our sample size for the confirmatory factor analysis was 591, so we interpreted other indices of model fit in favor of $\chi^{2}$. While internal consistency of the reactive factor was poor, the factor structure was replicated in the confirmatory factor analysis.

Previous research (Bender et al., 2011) has emphasized the role of impulsivity in leading to chosen or proactive painful and provocative events and eventual acquired capability for suicide. The factor analyses demonstrate that unchosen, reactive painful and provocative events, such as physical or sexual victimization, are an alternate path through which individuals may acquire the capability for suicide. 


\section{Implications for the Painful and Provocative Events Scale}

Next, correlations with theoretically related constructs were considered. In the Interpersonal-Psychological Theory of Suicidal Behavior painful and provocative events are said to lead to increased pain tolerance and decreased fear of death, constructs measured by the acquired capability for suicide scale. Criterion-related concurrent validity of the revised PPES factors would be demonstrated by large correlations with the ACSS and its factors. These correlations were greater than PPES-ACSS correlations obtained in previous studies (Bender et al., 2011; Van Orden et al., 2008a). The proactive PPES factor of the revised PPES was strongly correlated with total ACSS score and all three factors, while the reactive PPES factor was weakly correlated with the total ACSS score and two of the factors, and uncorrelated with the third ACSS factor. This result is evidence that the proactive experiences are associated with acquired capability and thus, are painful and provocative events. The reactive events are not similarly associated; nevertheless, the reactive items were moderately correlated with INQ-12 total score and subscale scores, BDI-II score, and SBQ-R total score. Such a finding indicates that reactive events in the present sample and are not "painful and provocative" in the sense that they did not substantially correlate with acquired capability for suicide. However, reactive events (e.g., physical and sexual abuse) are meaningful in that they correlate with (and may contribute to) suicidal desire as measured by the INQ-12, perceived burdensomeness as measured by the INQ12 subscale, depression as measured by BDI-II, and suicidal behavior as measured by SBQ-R.

We hypothesized that PPES-ACSS correlations could be improved by including more reactive items that were theoretically less tied to impulsiveness. Contradictory to this hypothesis, we found that both proactive and reactive events correlated weakly with trait impulsiveness, and that removing reactive events led to a higher PPES-ACSS correlation. In 
sum, the proactive events subscale most closely resembles the definition of painful and provocative events as leading to increased pain tolerance and decreased fear of death established by Van Orden et al. (2008a) and others. Reactive events are emotionally and physically painful, and they may provoke depression and suicidal desire. The experiencing of reactive events seems best suited to the suicidal desire part of the IPTS, while experiencing proactive events seems to contribute to fearlessness and the acquired capability for suicide. The results of the present study indicate that the construct validity of the PPES can be improved by including more proactive experiences, and removing reactive experiences.

\section{Hierarchical Regression Tests of IPTS}

The present study sought to test the ability of IPTS variables (ACSS and INQ-12) to account for variance in suicidal behavior above and beyond the variance accounted for depression, impulsiveness, fearless dominance, and demographic variables. ACSS and INQ-12 were found to significantly contribute $5.9 \%$ more variance in SBQ-R score than the other variables in the full undergraduate sample. Such a finding highlights the importance of the INQ12 and ACSS; these variables are accounting for a meaningful amount of variance in suicidal behavior that is not obtained by measuring depression or impulsiveness. This result replicates the findings by Van Orden et al. (2008a) that IPTS variables account for an additional 8\% of variance in suicidal behavior in outpatients. To our knowledge, the present study is the first test of the IPTS in an undergraduate sample to simultaneously use the measures (ACSS, INQ-12 burdensomeness and belonging) developed to test the IPTS.

We replicated our analyses in a subsample of cyberbullying victims. Cyberbullying victims were a higher risk population, as evidenced by rates of suicidal ideation with a plan $(17.9 \%)$ and suicide attempting $(6.9 \%)$ that were nearly twice the rate of the full college sample. 
We wondered whether IPTS variables would account for a similar amount of variance in suicidal behavior in cyberbullying victims, a high risk sample. The ACSS and INQ-12 again accounted for more than $5 \%$ of variance $(5.1 \%)$ in SBQ-R score above and beyond depression and impulsiveness. In this subsample ACSS was not a statistically significant predictor of SBQ-R total score. While the overall model accounted for less variance (5.1\%) in SBQ-R score than in the full undergraduate sample (5.9\%), the contribution of the IPTS variables remained approximately the same. This finding again demonstrates the importance of the IPTS variables and extends their applicability to a high-risk population, cyberbullying victims.

In both analyses, the INQ-12-ACSS interaction did not significantly contribute to the model. We hypothesize that the INQ-12-ACSS interaction was non-significant because so few of our participants were suicide attempters. According to the IPTS, suicide attempts occur when both suicidal desire and acquired capability are present. Our sample and subsample had more suicidal desire in the form of suicidal ideation, than the acquired capability theoretically implicated in suicide attempts. With so few attempters in a sample, it is unlikely that many participants experienced both suicidal desire and the acquired capability for suicide. In the cyberbullying victim subsample, ACSS score was not a significant predictor of SBQ-R total score. As we found in the factor and correlational analyses, cyberbullying victimization is more closely tied to and strongly correlated with suicidal desire as opposed to acquired capability. This predominantly female subsample had higher INQ-12 scores and lower ACSS scores than the full sample. The small sample size, in addition to the increased role of suicidal desire in this subsample, may account for the non-significant influence of acquired capability 


\section{Path Analysis Test of IPTS}

A path analysis predicting SBQ-R score with impulsivity and IPTS variables was conducted using Amos to test the IPTS. The three BIS factors were entered to predict proactive PPES, the three ACSS factors, and SBQ-R total. The proactive PPES was entered to predict the ACSS factors and SBQ-R total, while the ACSS factors were drawn to predict SBQ-R total score. In the other part of the model, reactive PPES was entered to predict the two INQ-12 subscales and SBQ-R total score, while the INQ-12 subscales were set to predict SBQ-R total (Figure 1). After iterative model adjustments, including the removal of model components that did not aid in the prediction of SBQ-R total score, the model in Figure 4 emerged as the best fitting model. This model shows that the ACSS fearlessness of death factor emerged as a significant predictor of SBQ-R total score, while the other ACSS did not. Fearlessness of death is half of the construct of acquired capability as defined by Van Orden et al. (2010) and others. Smith et al. (2013) note that many of the items indicating increased pain tolerance, the other half of the acquired capability construct, loaded on uninterpretable factors in their factor analysis. The exclusion of pain tolerance items from these factors may help explain why the general fearlessness and spectator violence factors did not significantly contribute to predicting SBQ-R total score. Proactive events were found to be a good predictor of the ACSS fearless of death factor, but not of SBQ-R total score. This finding may indicate that proactive events (e.g. playing sports or hunting) generally serve as protectors against suicidal behavior, but that they may also lead to the acquired capability for suicide in some participants.

Model fit was improved with INQ-12 burdensomeness, but not INQ-12 belonging as predictor of SBQ-R. This finding indicates that perceived burdensomeness was more predictive of SBQ-R total score than thwarted belonging. INQ-12 burdensomeness significantly mediated 
the relationship between reactive events and SBQ-R total score, indicating that reactive events contribute to the sense of burdensomeness that is implicated in suicidal behavior. Fearlessness of death also significantly mediated the relationship between reactive events and suicidal behavior, indicating that experiencing reactive events can contribute to a decreased fear of death or dying. The final model, which included only IPTS variables, accounted for $37 \%$ of the variance in SBQ-R score. Again, this result underscores the importance of IPTS variables to suicidal behavior.

\section{Limitations}

The present study was limited in several ways. The undergraduate sample was largely female, young, and ethnically and racially homogenous. Such characteristics were even more pronounced in the cyberbullying victim subsample. Results of the present study should be interpreted in light of the sample. While we hypothesize that the proactive and reactive factor structure of the PPES will hold across samples, the specific items that were retained are heavily influenced by the characteristics of the current sample and detract from construct representativeness. For example, hypothesized painful and provocative events such as chronic illnesses, chronic pain, miscarriages, and war exposure were dropped from our factor analyses after weak factor loadings. These events are likely much less prevalent in a sample of young college students than in a representative sample of United States citizens. In addition, acquired capability is a construct that is hypothesized to be cumulative. A young sample has not had as much time to acquire the capability for suicide as older samples. Furthermore, all participants were currently enrolled in courses offered by a state university. College and universities tend to foster multiple avenues of belonging, including general identification with the success of athletic teams (Joiner, Hollar, \& Van Orden, 2006). 
Only 38 individuals (3.1\%) in the present sample reported a prior suicide attempt. While suicide is a low base-rate phenomenon, it can be difficult to draw conclusions about suicide from the SBQ-R total score which measures suicide attempts, ideation, and an estimate of future suicide likelihood. It is likely, because of the low base-rate of attempters in our sample, that the hierarchical regression and path analyses revealed factors that were predictive of suicide ideation, attempts, and perceived likelihood of future suicide as opposed to only suicide attempts. Finally, the present study was correlational in nature. While findings may lend themselves to causal hypotheses, the absence of temporal precedence among variables prevented us from drawing causal conclusions.

\section{Future Directions}

The present study identified a two-factor structure of a revised 17-item painful and provocative events scale in a young, college sample. Further research is needed to determine whether the factor structure holds in a more representative general population sample, and which items are most representative of each factor in more diverse samples. Future research should examine the painful and provocative events scale in a population of suicide attempters, to determine whether specific events more strongly related to suicide attempts. Finally, more path analyses and structural equation models can be used to examine multiple facets of the hypothesized IPTS models at one time.

\section{Conclusion}

The present study examined the factor structure of the 24-item painful and provocative events scale with 30 additional items. A 17-item scale was developed with two distinct factors: an 11-item proactive events factor and a 6-item reactive events factor. This factor structure was replicated in a confirmatory factor analysis. The proactive factor strongly correlated with a 
measure of acquired capability for suicide, while the reactive factor more strongly correlated with suicidal desire. Both the proactive and reactive factor played important roles in predicting suicidal ideation and behavior. The proactive factor is strongly implicated in the development of fearlessness of death, while the reactive factor is weakly associated with the same construct. The reactive factor is more strongly implicated in the perception of oneself as a burden, a contribution to the desire to die by suicide.

Tests of the IPTS revealed that IPTS variables of acquired capability and suicidal desire account for meaningful variance in suicidal ideation and behavior beyond the influence of depression and impulsivity, in both undergraduates and cyberbullying victims. Such a finding extends the reach of the IPTS, rendering it applicable to a undergraduate students and to adult undergraduate cyberbullying victims. A path analysis indicated that IPTS variables (painful and provocative events, fearlessness of death, and perceived burdensomeness) contribute significantly to the prediction of suicidal ideation and behavior. The outcomes largely support the generalization of the interpersonal-psychological theory of suicide to undergraduate and high-risk samples, and suggest painful and provocative events as a meaningful area for future exploration. 


\section{References}

ABC News. (2007, November 19). Parents: Cyber bullying led to teen's suicide. $A B C$ News.

Retrieved from http://abcnews.go.com/GMA/story?id=38

82520\&page=1\#.TtYs81aeOW9

American Association of Suicidology (2009). Elderly suicide fact sheet. Retrieved from

American Association of Suicidology website: http://www.suicidology.org/c/document _library/get_file?folderId=235\&name=DLFE-487.pdf

American Association of Suicidology (2011). Youth suicidal behavior-fact sheet. Retrieved from American Association of Suicidology website: http://www.suicidology.org/ c/document_library/get_file?folderId=248\&name=DLFE-484.pdf

Anestis, M. D., Bryan, C. J., Cornette, M. M., \& Joiner, T. E. (2009). Understanding suicidal behavior in the military: An evaluation of Joiner's interpersonal-psychological theory of suicidal behavior in two cases of active duty post-deployers. Journal of Mental Health Counseling, 70(1), 60-75.

Beck, A. T., Steer, R. A., \& Brown G. K. (1996). Beck Depression Inventory-Second Edition Manual. San Antonio, TX: The Psychological Corporation.

Beck, A. T., Ward, C. H., Mendelson, M., Mock, J., \& Erbaugh, J. (1961). An inventory for measuring depression. Archieves of General Psychiatry, 4(6), 561-571. doi:10.1001/archpsyc.1961.01710120031004

Beck, A. T., Weissman, A., Lester, D., \& Trexler, L. (1974). The measurement of pessimism: The hopelessness scale. Journal of Consulting and Clinical Psychology, 42(5), 861-865. doi: $10.1037 / \mathrm{h} 0037562$ 
Bender, T. W., Anestis, M. D., Anestis, J. C., Gordon, K. H., \& Joiner, T. E. (2012). Affective and behavioral paths toward the acquired capability for suicide. Journal of Social and Clinical Psychology, 31(1), 81-100. doi:10.1521/jscp.2012.31.1.81

Bender, T. W., Gordon, K. H., Bresin, K., \& Joiner, T. E. (2011). Impulsivity and suicidality: The mediating role of painful and provocative experiences. Journal of Affective Disorders, 129, 301-307. doi: 10.1016/j.jad.2010.07.023

Bender, T.W. (2009). Suicidality and impulsivity: A test of the mediating role of painful and provocative events. Retrieved from Florida State University Electronic Theses, Treatises, and Dissertations: http://etd.lib.fsu.edu/theses/available/etd-04122009180947/unrestricted/BenderTthesis.pdf

Blouin, A. G., Perez, E. L., \& Blouin, J. H.(1988). Computerized administration of the diagnostic interview schedule. Psychiatry Research, 23(3), 335-344. doi: 10.1016/01651781(88)90024-8

Centers for Disease Control and Prevention. (2011). Suicidal thoughts and behaviors among adults aged $\geq 18$ years-United States, 2008-2009. Retrieved January 27, 2012, from http://www.cdc.gov/mmwr/PDF/ss/ss6013.pdf

Clark S.E., \& Goldney, R (2000). The impact of suicide on relatives and friends. In: Hawton K, Van Heeringen K, eds. The international handbook of suicide and attempted suicide. Chichester: Wiley, 467-84. doi: 10.1002/9780470698976.ch26

Cohen, J. (1988). Statistical power analysis for the behavioral sciences. Hillsdale, NJ: Erlbaum Crowne, D. P., Marlowe, D. (1960). A new scale of social desirability independent of psychopathology. Journal of Consulting Psychology, 24(4), 349-354. doi: $10.1037 / \mathrm{h} 0047358$ 
Cull, J. G., \& Gill, W. S. (1988). Suicide Probability Scale Manual. Los Angeles:

Western Psychological Services.

Floyd, F. J., \& Widaman, K. F. (1995). Factor analysis in the development and refinement of clinical assessment instruments. Psychological Assessment,7(3), 286-299. doi: 10.1037/1040-3590.7.3.286

Freedenthal, S., Lamis, D. A., Osman, A., Kahlo, D., \& Gutierrez, P. M. (2011). Evaluation of the psychometric properties of the interpersonal-needs-questionnaire-12 in samples of men and women. Journal of Clinical Psychology, 67(6), 609-623. doi: 10.1002/jclp.20782

Furr, R. (2011). Scale construction and psychometrics for social and personality psychology. Los Angeles: SAGE.

G*Power (Version 3.1.3) [Computer Software]. Germany: Universität Kiel.

Hayes, A.F. (2013). An introduction to mediation, moderation, and conditional process analysis: A regression-based approach. New York: Guilford Press. http://www.guilford.com/ Hinduja, S. \& Patchin, J. W. (2010). Bullying, cyberbullying, and suicide. Archives of Suicide Research, 14, 206-221. doi: 10.1080/13811118.2010.494133

Joiner, T. E. (2005). Why people die by suicide. Cambridge, Mass: Harvard University Press. Joiner, Jr., T. E., Hollar, D., \& Van Orden, K. A. (2006). On Buckeyes, Gators, Super Bowl Sunday, and the Miracle on Ice: "Pulling Together" is associated with lower suicide rates. Journal of Social and Clinical Psychology, 25, 180-196. doi: $10.1521 /$ jscp.2006.25.2.179

Joiner, T. E., Van Orden, K. A., Witte, T. K., Selby, E. A., Ribeiro,...Rudd, M. D. (2009). Main predictions of the Interpersonal-Psychological Theory of suicidal behavior: Empirical 
tests in two samples of young adults. Journal of Abnormal Psychology, 118(3), 634-646. doi: $10.1037 / \mathrm{a} 0016500$

Kessler, R. C., McGonagle, K. A., Zhao, S., Nelson, C. B., Hughes, M., Eshleman, S.,...Kendler, S. (1994). Lifetime and 12-month prevalence of DSM-III-R psychiatric disorders in the United States. Archives of General Psychiatry, 51(1), 8-19. doi:

10.1001/archpsyc.1994.03950010008002

Kim, Y. S. \& Leventhal, B. (2008). Bullying and suicide: A review. International Journal of Adolescent Mental Health, 20(2), 133-154. Retrieved from: http://www.equalitytexas.org/app_themes/images/site/10/pages/10/Bullying-Suicide.pdf

Kopta, S.M., \& Lowry, J.L. (2002). Psychometric evaluation of the Behavioral Health Questionnaire-20: A brief, comprehensive instrument for assessing mental health. Psychotherapy Research, 12(4), 413-426. doi: 10.1093/ptr/12.4.413

Kraft, E. \& Wang, J. (2010). An exploratory study of the cyberbullying and cyberstalking experiences and factors related to victimization of students at a public liberal arts college. International Journal of Technologies, 1(4), 74-91. doi: 10.4018/jte.2010100106

Lijffijt, M. (2012). BIS-11A to BIS-11 scoring [Fact sheet]. Retrieved March 28, 2013, from The International Society for Research on Impulsivity website: http:/www.impulsivity.org/pdf/ BIS-11Aprioration.pdf

Lilienfeld, S. O., \& Widows, M. R. (2005). Psychopathic Personality Inventory-Revised: Professional Manual. Lutz, FL: Psychological Assessment Resources, Inc.

Lindeman, S., Laeaerae, E., Hakko, H., \& Lonnqvist, J. (1996). A systematic review on genderspecific suicide mortality in medical doctors. British Journal of Psychiatry, 168, 274 279. doi: 10.1192/bjp.168.3.274 
Linehan, M. M., Goodstein, J. L., Nielsen, S. L., \& Chiles, J. A. (1983). Reasons for staying alive when you are thinking of killing yourself: The Reasons for Living Inventory. Journal of Consulting and Clinical Psychology, 51(2), 276-186. doi: 10.1037/0022006X.51.2.276

MacCallum, R. C., Widaman, K. F., Zhang, S. \& Hong, S. (1997). Sample size in factor analysis. Psychological Methods, 4(1), 84-99. doi: 10.1037/1082-989X.4.1.84

Millon, T. (1983). Millon Clinical Multiaxial Inventory. Minneapolis, MN: Interpretive Scoring Systems.

Osman, A., Bagge, C. L., Gutierrez, P. M., Konick, L. C., Kopper, B. A., \& Barrios, F. X. (2001). The Suicidal Behaviors Questionnaire-Revised (SBQ-R): Validation with clinical and non-clinical samples. Assessment, 8(4), 443-454. doi: 10.1177/107319110100800409

Patton, J. H., Stanford, M. S., \& Barratt, E. S. (1995). Factor structure of the Barratt Impulsiveness Scale. Journal of Clinical Psychology, 51(6), 768-774. doi: 10.1002/10974679(199511)51:6<768::AID-JCLP2270510607>3.0.CO;2-1

Privitera, C., \& Campbell, M.A. (2009). Cyberbullying: The new face of workplace bullying?. CyberPsychology and Behavior, 12, 395-400. doi: 10.1089/cpb.2009.0025

Rossotto, E., Yager, J., \& Rorty, M. (1998). The Impulsive Behavior Scale. In: Vanderlinden, J., Vandereycken, W. (Eds.), Trauma, dissociation, and impulse dyscontrol in eating disorders. Brunner/Mazel, Levittown, PA.

Schenk, A. M., \& Fremouw, W. J. (2012). Prevalence, psychological impact, and coping of cyberbully victims among college students. Journal of School Violence, 11(1), 21-37. doi: $10.1080 / 15388220.2011 .630310$ 
Schumacker, R. \& Lomax, R. (2004). A beginner's guide to structural equation modeling. Mahwah, N.J: Lawrence Erlbaum Associates

Schwartz, J. (2010, October 2). Bullying, suicide, punishment. The New York Times. Retrieved from http://www.nytimes.com/2010/10/03/weekinreview/03schwartz.html

Smith, P. N., Wolford-Clevenger, C., Mandracchia, J. T., \& Jahn, D. R. (2013). An exploratory factor analysis of the acquired capability for suicide scale in male prison inmates. Psychological Services, 10(1), 97-105. doi: 10.1037/a0030817

Sprinkle, S. D., Lurie, D., Insko, S. L., Atkinson, G., Jones, G. L., Logan, A. R., \& Bissada, N. N. (2002). Criterion validity, severity cut scores, and test-retest reliability of the Beck Depression Inventory-II in a university counseling center sample. Journal of Counseling Psychology, 49(3), 381-385. doi: 10.1037/0022-0167.49.3.381

Storch, E. A., Roberti, J. W., \& Roth, D. A. (2004). Factor structure, concurrent validity, and internal consistency of the Beck Depression Inventory - second edition in a sample of college students. Depression and Anxiety, 19(3), 187-189. doi: 10.1002/da.20002

Van Orden, K. A., Witte, T. K., Curkrowicz, K. C., Braithwaite, S. R., Selby, E. A., \& Joiner, T. E. (2010). The interpersonal theory of suicide. Psychological Review, 117(2), 575-600. doi: $10.1037 / \mathrm{a} 0018697$

Van Orden, K. A., Witte, T. K., Gordon, K. H., Bender, T. W., \& Joiner, T. E. (2008a). Suicidal desire and the capability for suicide: A test of the interpersonal psychological theory in adults. Journal of Consulting and Clinical Psychology, 76, 72-83. doi: 10.1037/0022006X.76.1.72

Van Orden, K. A., Witte, T. K., James, L. M., Castro, Y., Gordon, K. H., Braithwaite, S.R., ...Joiner, T.E. (2008b). Suicidal ideation in college students varies across semesters: The 
mediating role of belonging. Suicide and Life-Threatening Behavior, 38(4), 427-435. doi: 10.1521/suli.2008.38.4.427

Witte, T. K., Merrill, K. A., Stellrecht, N. E., Bernert, R. A., Hollar, D. L., Schatschneider, C., \& Joiner, T. E. (2008). "Impulsive" youth suicide attempters are not necessarily all that impulsive. Journal of Affective Disorders, 107, 107-116. doi:10.1016/j.jad.2007.08.010

Zuckerman, M. (2002). Zuckerman-Kuhlman personality questionnaire (ZKPQ): An alternative five-factorial model. In B. de Raad, \& M. Perugini (Eds.), Big five assessment (pp. 376392). Ashland, OH: Hogrefe \& Huber Publishers. 
Table 1

Demographic information of full sample and cyberbullying victim subsample.

\begin{tabular}{|c|c|c|c|c|}
\hline & \multicolumn{2}{|c|}{$\begin{array}{c}\text { Full Sample } \\
(\mathrm{N}=1211)\end{array}$} & \multicolumn{2}{|c|}{$\begin{array}{l}\text { Cyberbullying Victim Subsample } \\
\qquad(\mathrm{N}=173) \\
\end{array}$} \\
\hline & $\underline{M(S D)}$ & Range & $M(S D)$ & Range \\
\hline Age & $19.50(2.09)$ & $18-39$ & $19.03(1.27)$ & $18-26$ \\
\hline & $\mathbf{N}$ & $\%$ & $\mathbf{N}$ & $\%$ \\
\hline \multicolumn{5}{|l|}{ Gender } \\
\hline Female & 889 & 73.4 & 151 & 87.3 \\
\hline Male & 321 & 26.5 & 21 & 12.1 \\
\hline Other/Missing & 1 & 0.1 & 1 & 0.6 \\
\hline \multicolumn{5}{|l|}{ Ethnicity } \\
\hline White/Caucasian & 1085 & 89.6 & 156 & 90.2 \\
\hline Black/African American & 36 & 3.0 & 1 & 0.6 \\
\hline Latino/Hispanic & 23 & 1.9 & 5 & 2.9 \\
\hline Asian American & 20 & 1.7 & 3 & 1.7 \\
\hline Native American & 4 & 0.3 & 2 & 1.2 \\
\hline Other/Missing & 43 & 3.5 & 6 & 3.5 \\
\hline \multicolumn{5}{|l|}{ Academic Class } \\
\hline Freshman & 434 & 35.8 & 79 & 45.7 \\
\hline Sophomore & 423 & 34.9 & 58 & 33.5 \\
\hline Junior & 218 & 18.0 & 26 & 15.0 \\
\hline Senior & 122 & 10.1 & 10 & 5.8 \\
\hline Other/Missing & 12 & 1.2 & 0 & 0.0 \\
\hline Prior Suicide Attempt & 38 & 3.1 & 12 & 6.9 \\
\hline Suicidal Ideation with Plan & 110 & 9.1 & 31 & 17.9 \\
\hline
\end{tabular}


Table 2

Pattern Matrix of Factor Loadings for Exploratory Factor Analysis of Revised Painful and

Provocative Events Scale $(N=620)$

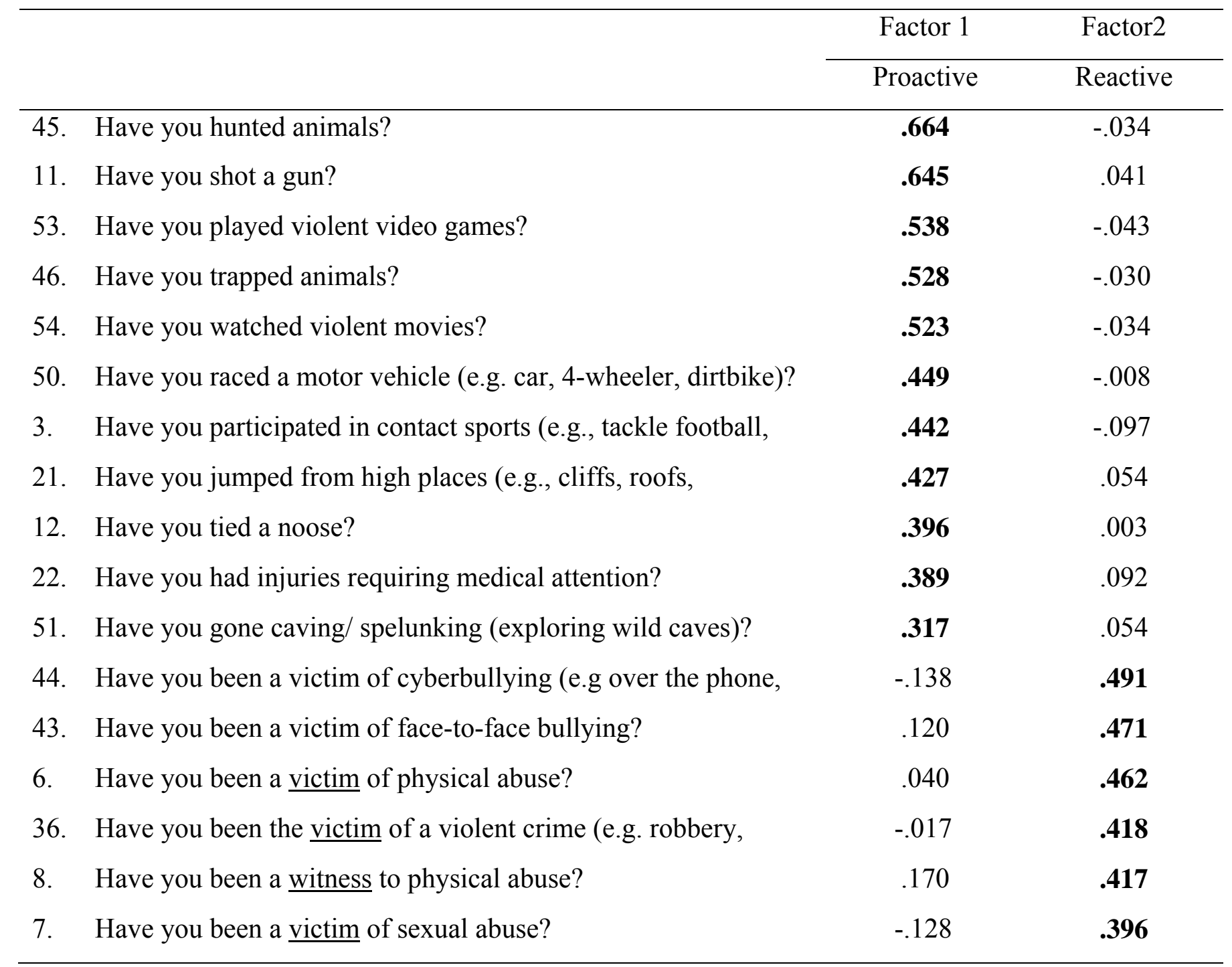

Note. .30 was used as a criterion for inclusion onto a factor. Bolded numbers indicate factor loadings greater than .30 . 
Table 3

Factor Loadings for Confirmatory Factor Analysis of Revised Painful and Provocative Events Scale $(N=591)$

\begin{tabular}{|c|c|c|c|}
\hline & \multirow{2}{*}{$\begin{array}{l}\text { Factor } 1 \\
\text { Proactive }\end{array}$} & \multirow{2}{*}{$\begin{array}{l}\text { Factor2 } \\
\text { Reactive }\end{array}$} \\
\hline & & & \\
\hline 11. & Have you shot a gun? & .615 & -- \\
\hline 46. & Have you trapped animals? & .555 & -- \\
\hline 21. & Have you jumped from high places (e.g., cliffs, roofs, & .527 & -- \\
\hline 45. & Have you hunted animals? & .505 & -- \\
\hline 50. & Have you raced a motor vehicle (e.g. car, 4-wheeler, dirtbike)? & .494 & -- \\
\hline 51. & Have you gone caving/ spelunking (exploring wild caves)? & .408 & -- \\
\hline 53. & Have you played violent video games? & .373 & -- \\
\hline 22. & Have you had injuries requiring medical attention? & .354 & -- \\
\hline 3. & Have you participated in contact sports (e.g., tackle football, & .321 & -- \\
\hline 54. & Have you watched violent movies? & .309 & -- \\
\hline 12. & Have you tied a noose? & .223 & -- \\
\hline 6. & Have you been a victim of physical abuse? & -- & .681 \\
\hline 8. & Have you been a witness to physical abuse? & -- & .575 \\
\hline 7. & Have you been a victim of sexual abuse? & -- & .564 \\
\hline 36. & Have you been the victim of a violent crime (e.g. robbery, & -- & .359 \\
\hline 43. & Have you been a victim of face-to-face bullying? & -- & .345 \\
\hline 44. & Have you been a victim of cyberbullying (e.g over the phone, & -- & .234 \\
\hline
\end{tabular}

Note. Bolded numbers indicate factor loadings greater than .30. 
Table 4

Means and Standard Deviations for, and Intercorrelations Between, Full Sample Variables of Interest $(N=1211)$

\begin{tabular}{|c|c|c|c|c|c|c|c|c|c|c|c|c|c|c|c|c|c|c|}
\hline & 1 & 2 & 3 & 4 & 5 & 6 & 7 & 8 & 9 & 10 & 11 & 12 & 13 & 14 & 15 & 16 & 17 & 18 \\
\hline 1.Age & -- & & & & & & & & & & & & & & & & & \\
\hline 2. Gender & -.01 & -- & & & & & & & & & & & & & & & & \\
\hline 3. PPES Proactive & .03 & $-.52 * *$ & -- & & & & & & & & & & & & & & & \\
\hline 4. PPES Reactive & .09 & $.07 *$ & $.13 * *$ & -- & & & & & & & & & & & & & & \\
\hline 5. SBQ-R & .04 & .05 & .04 & $.36^{* *}$ & -- & & & & & & & & & & & & & \\
\hline 6. BDI-II & $.09^{* *}$ & $.14^{* *}$ & .01 & $.33^{* *}$ & $.54 * *$ & -- & & & & & & & & & & & & \\
\hline 7. INQ-12 & $.09 * *$ & .00 & .01 & $.25^{* *}$ & $.54 * *$ & $.65^{* *}$ & -- & & & & & & & & & & & \\
\hline Burden & .04 & .05 & .02 & $.25^{* *}$ & $.57 * *$ & $.65^{* *}$ & $.91 * *$ & -- & & & & & & & & & & \\
\hline Belonging & $.11^{* *}$ & $-.05^{*}$ & .00 & $.19^{* *}$ & $.41^{* *}$ & $.54 * *$ & $.90 * *$ & $.65^{* *}$ & -- & & & & & & & & & \\
\hline 10. ACSS & .03 & $-.43 * *$ & $.56^{* *}$ & $.09 * *$ & $.12 * *$ & .01 & .04 & .05 & .03 & -- & & & & & & & & \\
\hline General Fearless & .03 & $-.21 * *$ & $.42 * *$ & $.12 * *$ & $.10 * *$ & .02 & .01 & .02 & .00 & $.68^{* *}$ & -- & & & & & & & \\
\hline Death Fearless & $.08 * *$ & $-.30 * *$ & $.35^{* *}$ & $.10^{* *}$ & $.11 * *$ & -.01 & .03 & .04 & .02 & $.75^{* *}$ & $.34 * *$ & -- & & & & & & \\
\hline 13. Spectator Violence & $-.09 * *$ & $-.36^{* *}$ & $.46^{* *}$ & .05 & .00 & .02 & -.02 & .00 & -.03 & $.57 * *$ & $.31 * *$ & $.23 * *$ & -- & & & & & \\
\hline 14. BIS & -.03 & -.02 & $.13 * *$ & $.16^{* *}$ & $.16^{* *}$ & $.33 * *$ & $.22 * *$ & $.23 * *$ & $.18^{* *}$ & $.13^{* *}$ & $.12 * *$ & .03 & $.20 * *$ & -- & & & & \\
\hline Motor & -.01 & $-.07 *$ & $.17 * *$ & $.16^{* *}$ & $.10^{* *}$ & $.20 * *$ & $.13^{* *}$ & $.14 * *$ & $.10^{* *}$ & $.17^{* *}$ & $.16^{* *}$ & $.08 * *$ & $.22 * *$ & $.79 * *$ & -- & & & \\
\hline Attentional & .01 & -.03 & $.13 * *$ & $.18^{* *}$ & $.24 * *$ & $.42 * *$ & $.30 * *$ & $.28 * *$ & $.27 * *$ & $.12 * *$ & $.14 * *$ & .05 & $.17 * *$ & $.76^{* *}$ & $.45^{* *}$ & -- & & \\
\hline Non-Planning & .03 & -.02 & .02 & $.09^{* *}$ & $.14^{* *}$ & $.29 * *$ & $.26^{* *}$ & $.24 * *$ & $.24 * *$ & .04 & -.01 & -.04 & $.09 * *$ & $.81^{* *}$ & $.48^{* *}$ & $.57 * *$ & -- & \\
\hline 18. PPI-R FD & $-.08 * *$ & $-.29 * *$ & $.46^{* *}$ & $.08^{* *}$ & $.09 * *$ & .05 & $.06^{*}$ & $.06^{*}$ & .05 & $.56^{* *}$ & $.52 * *$ & $.32 * *$ & $.38^{* *}$ & $.34 * *$ & $.37 * *$ & $.25^{* *}$ & $.20 * *$ & -- \\
\hline MEAN & 19.51 & -- & 11.86 & 2.83 & 4.54 & 9.06 & 21.97 & 11.67 & 10.30 & 34.94 & 4.60 & 4.66 & 3.70 & 63.83 & 16.31 & 11.82 & 19.39 & 32.11 \\
\hline$S D$ & 2.09 & -- & 6.26 & 2.60 & 2.40 & 8.47 & 11.16 & 6.33 & 5.96 & 9.86 & 2.87 & 3.58 & 2.77 & 8.19 & 3.03 & 2.30 & 4.26 & 8.58 \\
\hline
\end{tabular}

Note. PPES = Painful and Provocative Events Scale (Proactive and Reactive factors); SBQ-R = Suicidal Behaviors Questionnaire Revised; BDI-II = Beck Depression Inventory-II; INQ-12 = Interpersonal Needs Questionnaire (Perceived Burdensomeness and Thwarted Belongingness subscales); ACSS = Acquired Capability for Suicide Scale (General Fearlessness/Perceived Pain Tolerance, Fearlessness of Death, and Spectator Enjoyment of Violence factors); BIS = Barratt Impulsiveness Scale (Motor Impulsiveness, Cognitive/Attentional Impulsiveness, and Non-Planning Impulsiveness subscales); PPI-R FD = Psychopathic Personality Inventory-Revised Fearless Dominance subscale. $*=$ significant at $p<.05 ; * *=$ significant at $p<$ .01 . 
Table 5

Hierarchical Multiple Regression Equation Predicting SBQ-R Score in a Sample of 1079 Undergraduate Cyberbullying Victims

\begin{tabular}{|c|c|c|c|c|c|}
\hline Predictors entered in set & $F$ for set & $R^{2}$ & $\begin{array}{c}t \text { for } \\
\text { predictors }\end{array}$ & $d f$ & $p$ \\
\hline 1 & 83.03 & .276 & & 5,1073 & $.000 * *$ \\
\hline Age & & & -0.40 & & .691 \\
\hline Gender & & & 2.00 & & .046 \\
\hline Depression (BDI-II) & & & 9.14 & & $.000 * *$ \\
\hline Barratt Impulsiveness Scale (BIS) & & & 0.58 & & .563 \\
\hline PPI-R Fearless Dominance Scale & & & -0.91 & & .361 \\
\hline 2 & 78.40 & .334 & & 7,1071 & $.000 * *$ \\
\hline Interpersonal Needs (INQ) & & & 9.08 & & $.000 * *$ \\
\hline Acquired Capability (ACSS) & & & 3.32 & & $.001 * *$ \\
\hline 3 & 68.92 & .335 & & 8,1070 & $.000 * *$ \\
\hline ACSS*INQ & & & 1.43 & & .152 \\
\hline
\end{tabular}

Note. $f^{2}$ effect size of .50 for model 3, a large effect (Cohen, 1988). 
Table 6

Hierarchical Multiple Regression Equation Predicting SBQ-R Score in a Subsample of 156 Undergraduate Cyberbullying Victims

\begin{tabular}{|c|c|c|c|c|c|}
\hline Predictors entered in set & $F$ for set & $R^{2}$ & $\begin{array}{c}t \text { for } \\
\text { predictors }\end{array}$ & $d f$ & $p$ \\
\hline 1 & 7.91 & .182 & & 5,150 & $.000 * *$ \\
\hline Age & & & 0.36 & & .718 \\
\hline Gender & & & 0.24 & & .814 \\
\hline Depression (BDI-II) & & & 2.82 & & $.006 * *$ \\
\hline Barratt Impulsiveness Scale (BIS) & & & -0.22 & & .827 \\
\hline PPI-R Fearless Dominance Scale & & & 0.46 & & .645 \\
\hline 2 & 7.88 & .237 & & 7,148 & $.000^{* *}$ \\
\hline Interpersonal Needs (INQ) & & & 3.00 & & $.003 * *$ \\
\hline Acquired Capability (ACSS) & & & 1.46 & & .146 \\
\hline 3 & 6.88 & .233 & & 8,147 & $.000^{* *}$ \\
\hline ACSS*INQ & & & 0.46 & & .643 \\
\hline
\end{tabular}

Note. $f^{2}$ effect size of .30 for model 3, a large effect (Cohen, 1988). 


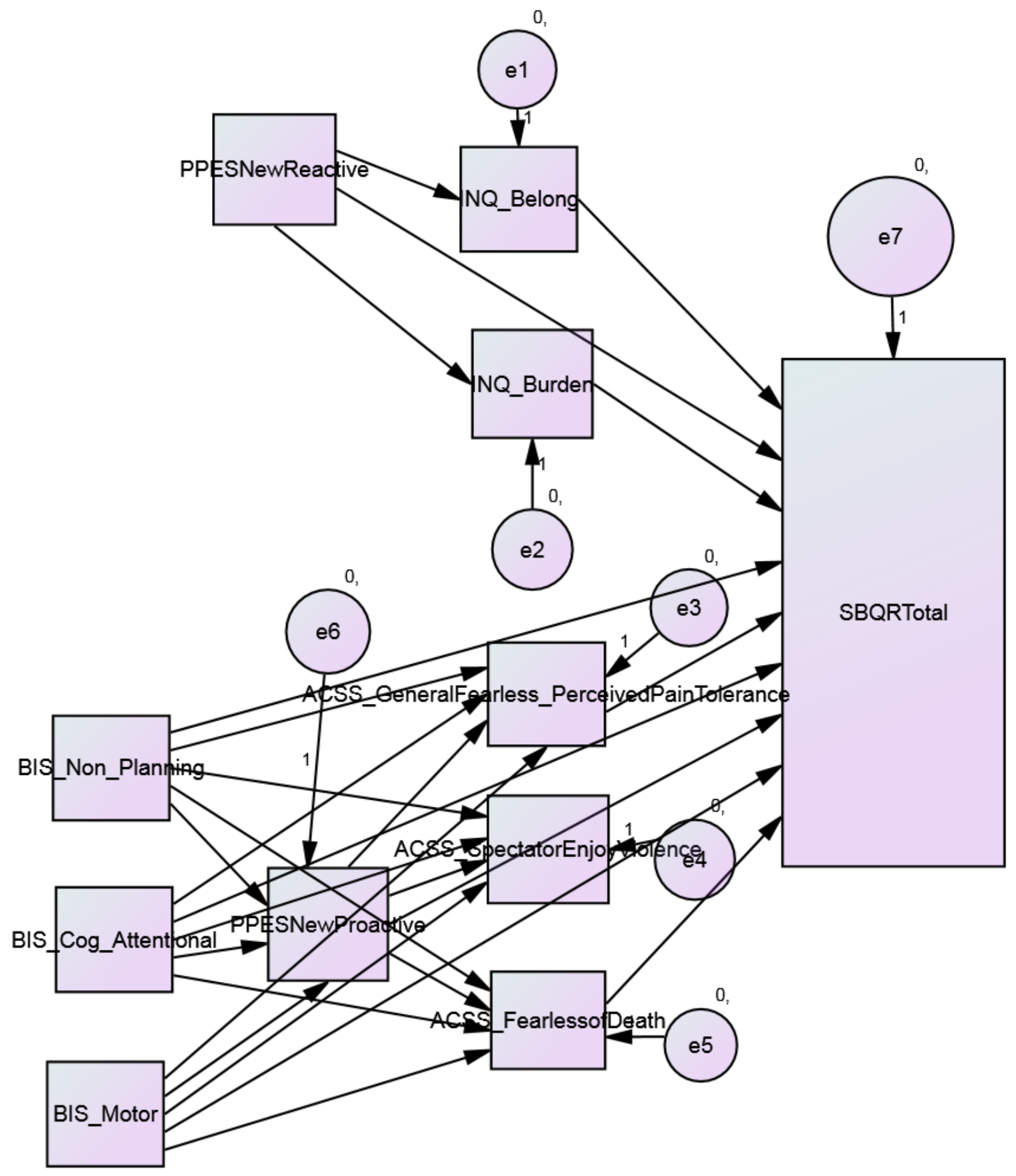

Figure 1. Original specified model for path analysis to test IPTS by predicting SBQ-R total score from observed IPTS predictor variables. 


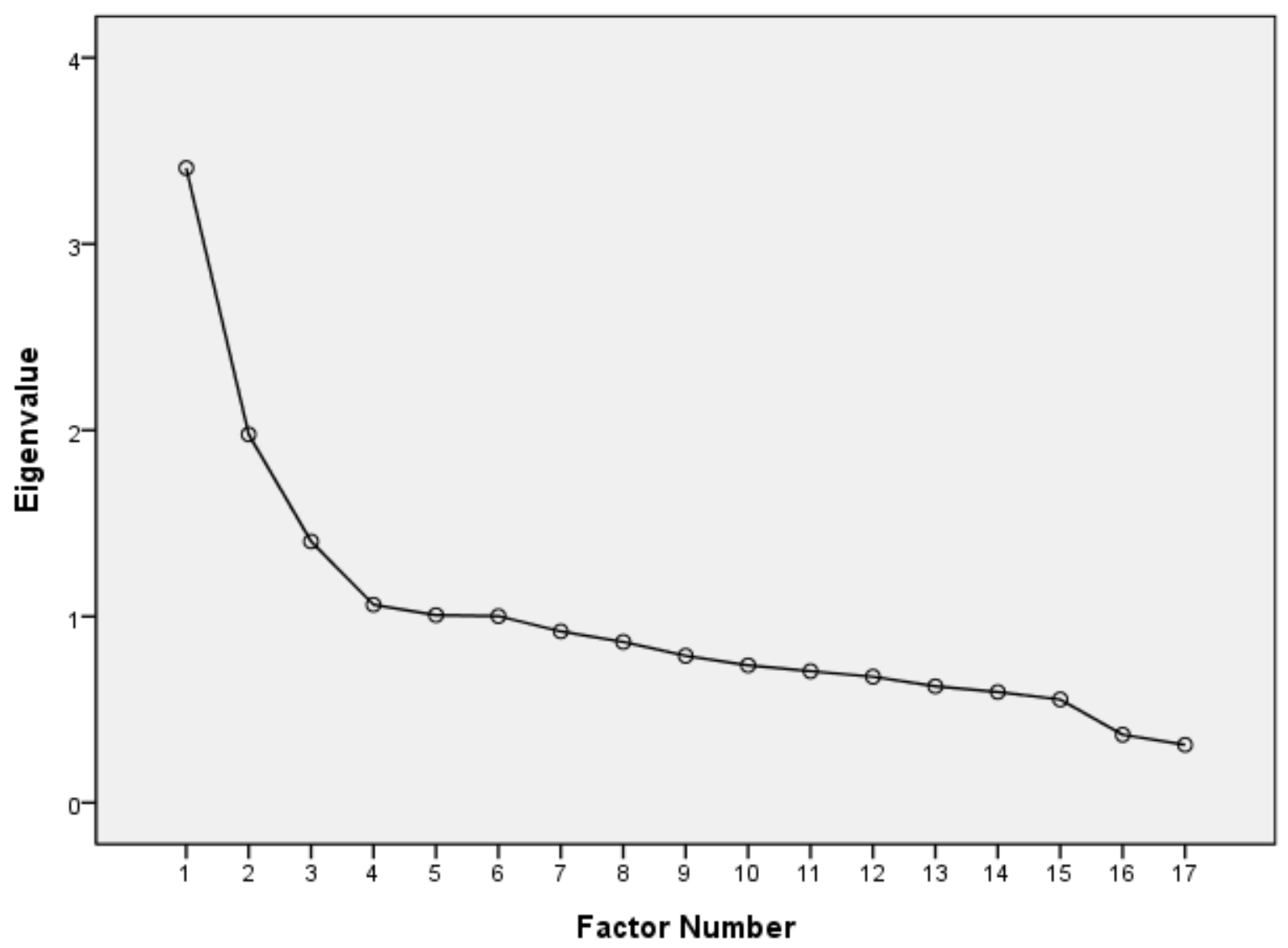

Figure 2. Scree plot for exploratory factor analysis of revised painful and provocative events scale. 

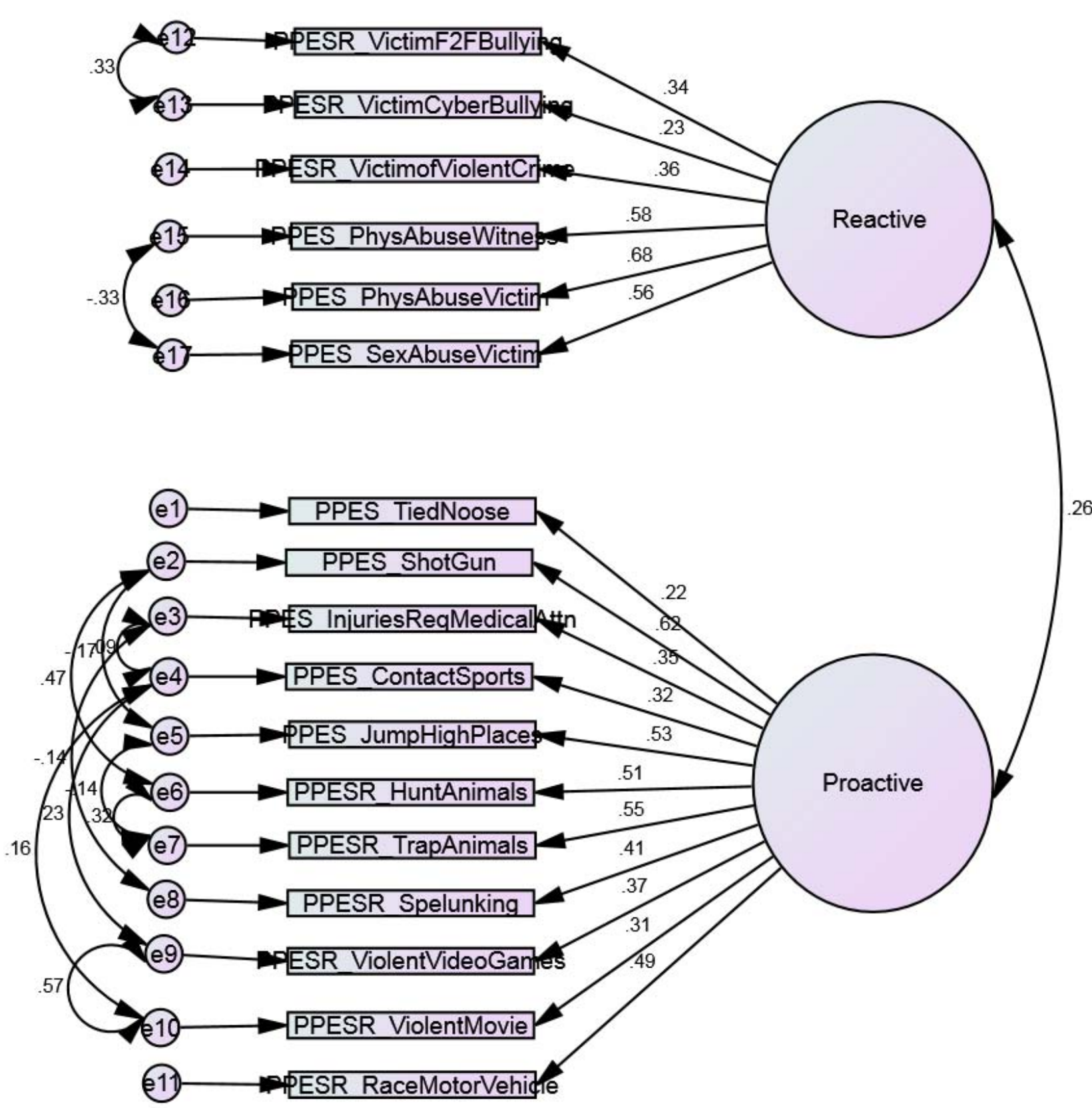

Figure 3. Confirmatory factor analysis for painful and provocative events scale. Large circles represent latent proactive and reactive factors. Rectangles represent scale items. Small circles represent error terms. Numbers indicate standardized regression weights. 


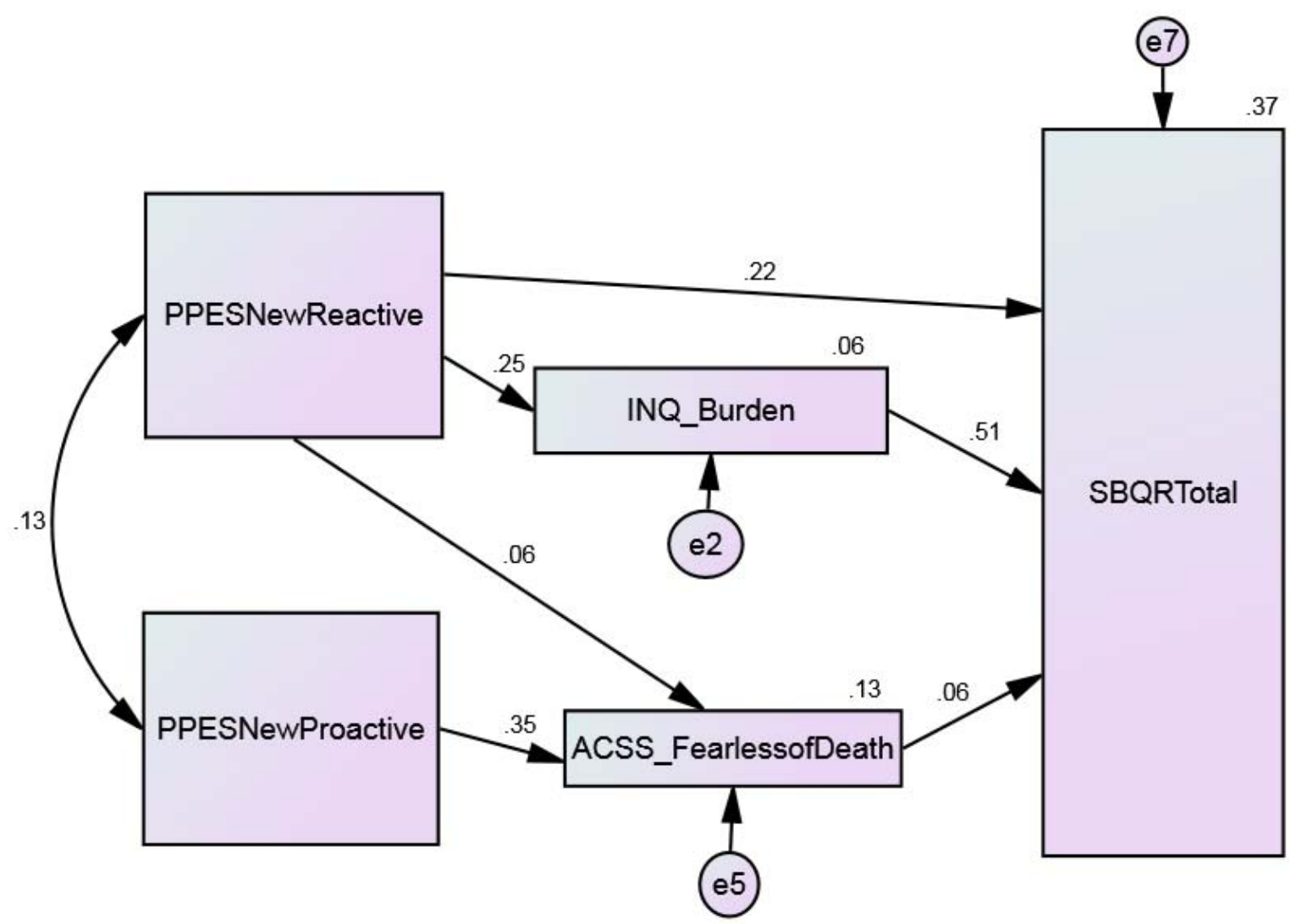

Figure 4. Final specified path analysis of IPTS variables predicting SBQ-R score. The numbers are standardized regression weights among observed variables. The predictors in the model account for $37 \%$ of the variance in SBQ-R total score. 


\section{APPENDIX A \\ Internet Experiences Questionnaire (IEQ)}

The following questions address information regarding your personal characteristics and experiences. Please answer the following questions as honestly as possible. If you feel uncomfortable answering any questions you may decline to answer it.

1. What is your age?

2. What is your gender? (check one):

Female

Male

3. With what ethnic group do you most closely identify? (check one)

White/Caucasian Native American
Black/African American

Asian American
Latino/Hispanic Other

4. Marital Status: (check one):

Single

Married

Separated

Divorced

Widowed

5. What is your current class status? (check one):

Freshman Sophomore Junior Senior

Graduate Student Other

6. What is your current GPA?

7. Have you ever sought mental health counseling?

Yes No

8. Approximately how many hours are you online on a typical day?

9. On average, how much money do you spend each month on Internet and cell phone bills?

\section{YOUR EXPERIENCES (PERPETRATOR SECTION)}

10. In the past 2 years, how many times have you:

a. Sent mean, nasty, or harassing messages to someone via the internet or cellular phone?

$$
\begin{array}{llllll}
0 & 1 & 2-3 & 4-7 & 8-14 & 15 \text { or more }
\end{array}
$$

b. Put down someone else online by sending or posting cruel gossip, rumors, or other harmful material?

$$
\begin{array}{llllll}
0 & 1 & 2-3 & 4-7 & 8-14 & 15 \text { or more }
\end{array}
$$

c. Pretended to be someone else online to send or post material to damage that person's reputation or friendships?

$$
\begin{array}{llllll}
0 & 1 & 2-3 & 4-7 & 8-14 & 15 \text { or more }
\end{array}
$$

d. Shared someone's personal secrets or images online without that person's permission?

$$
\begin{array}{llllll}
0 & 1 & 2-3 & 4-7 & 8-14 & 15 \text { or more }
\end{array}
$$

11. How many different people did you do these things to using the internet or cell phones? 


\section{$\begin{array}{lllll}0 & 1 & 2-3 & 4-6 & 7 \text { or more }\end{array}$}

12. What methods of technology did you use to send harassing or mean messages to others and/or to post material to damage the reputation/relationships of others? (Please select all that apply):

Email

Instant messaging

Social networking sites

Blogs/website creation

Text messaging

Picture messaging

Video messaging

Repeated phone calls (prank calling)

I have never sent harassing or mean messages or posted material to damage

relationships/reputations of others.

13. If you have pretended to be someone else online to send or post material to damage that person's reputation or friendships, who did you pretend to be?

I've never pretended to be someone else online

I pretended to be the person I was posting information about

I pretended to be a member of the opposite sex seeking a relationship

I pretended to be one of their friends

Other: Please describe:

Not applicable

14. What were your reasons for doing these behaviors via the Internet/Cellular phones? (please select all that apply):

Anger

Jealousy

Revenge

Hatred

Dislike for the other person

Sadness

Attention

Boredom

To try to make up with an ex-boyfriend/girlfriend

To try to disrupt/ruin a friendship

To try to disrupt/ruin a romantic relationship

Revenge for being bullied by others

Other: Please describe

Not applicable 
15. How do you think this impacted the other person? (If this question is not applicable to you, please select 'decline to answer'):

16. What were your reasons for choosing who to send mean/harassing messages to, posting material to damage the reputation/relationships of others, etc. (please select all that apply):

You disliked them

You were mad at them

To get revenge

To hurt the person

They are a weak/less powerful individual

They physically bullied you

They were annoying

Other: Please describe:

Not applicable

17. If you stopped, why did you stop? (If this question is not applicable to you, please select 'decline to answer') :

18. Did you stop for any of the following reasons? (Please select all that apply) No longer $\mathrm{mad} / \mathrm{upset}$

Got bored with it Could no longer contact the person

Didn't want to hurt the persons feelings

Got caught by parents or other adults

Got caught by the police

Other: Please describe:

Not applicable

\section{Your Experiences}

For this section, bullying is when someone repeatedly says mean or hurtful things to another individual. This includes teasing, hitting or fighting, threats, leaving you out on purpose, or telling lies or starting rumors about you.

19. In the past 2 years, have you ever been bullied?

Yes No

20. Have you ever been bullied in middle school and/or high school?

Yes No

Cyberbullying is defined as repeatedly harassing someone using technology such as email, instant messaging, social networking sites, blogs, other websites, cell phones, text messaging, picture messaging, video messaging, etc. with the intent of harming, embarrassing, or damaging 
the other individual. Cyberbullying also includes a person pretending to be someone they are not to embarrass, harass, or harm others.

\section{TEXT MESSAGING}

21. In the past 2 years, have you received harassing, mean, or nasty text-messages?

$$
\text { Yes No }
$$

22. How many times did this occur?

$$
\begin{array}{llllll}
0 & 1 & 2-3 & 4-7 & 8-14 & 15 \text { or more }
\end{array}
$$

23. If yes to Question __, who sent the harassing, mean, or nasty text messages to you? (Please check all that apply)

Ex-Boyfriend/Girlfriend

Neighbor

Not applicable
Friend/former friend Uncertain
Classmate

Other (please describe):

\section{INTERNET}

24. In the past 2 years, have you ever been had someone create a website about you, use your pictures on-line without your permission, post damaging or embarrassing information about you, create forums about you, repeatedly send you harassing emails or instant messages, receive abusive chat room messages, etc?

Yes No

25. How many times did this occur?

$$
\begin{array}{llllll}
0 & 1 & 2-3 & 4-7 & 8-14 & 15 \text { or more }
\end{array}
$$

26. If yes to Question __, who was doing it? (Please check all that apply) Ex-Boyfriend/Girlfriend Neighbor Friend/former friend Uncertain Classmate Not applicable

Other (please describe):

\section{PICTURE/VIDEO PHONES}

27. In the past 2 years, have you ever had someone take embarrassing or degrading pictures or videos of you with picture/video phones without your permission and show the pictures/videos to others to embarrass you? Yes No

28. How many times did this occur?

$$
\begin{array}{llllll}
0 & 1 & 2-3 & 4-7 & 8-14 & 15 \text { or more }
\end{array}
$$

29. If yes to Question ___, who was doing it? (Please check all that apply) Ex-Boyfriend/Girlfriend Neighbor Friend/former friend Uncertain Classmate Not applicable Other (please describe): 


\section{PHONE CALLS}

30. In the past 2 years, have you ever been repeatedly called on your mobile phone by a person/people not saying anything or leaving nasty/upsetting messages? Yes No

31. How many times did this occur?

$$
\begin{array}{llllll}
0 & 1 & 2-3 & 4-7 & 8-14 & 15 \text { or more }
\end{array}
$$

32. If yes to Question __, who was doing it? (Please check all that apply) Ex-Boyfriend/Girlfriend Neighbor Friend/former friend Classmate Uncertain Other (please describe): Not applicable

\section{MASQUERADING}

33. In the past 2 years, have you ever had someone pretend to be someone they were not and post or send material to damage your friendships or reputation, and/or hurt or embarrass you? Yes No

34. How many times did this occur?
0
$12-3$
$4-7$
$8-14$
15 or more

35. If yes to Question , who was doing it? (Please check all that apply) Ex-Boyfriend/Girlfriend Neighbor Friend/former friend Uncertain Classmate Not applicable

36. If you have encountered someone using the internet or cellular phones pretending to be someone they were not, did they pretend to be you or someone else?
$\mathrm{Me}$
Someone else
Both

\section{GENERAL CYBERBULLYING}

37. In the past 2 years, have you experienced cyberbullying?
Yes
No

38. Since middle school and/or high school, have you ever experienced cyberbullying?

Yes No

39. If you have been cyberbullied in any way (texts, pictures or video-clips, email, website, chat-rooms, mobile phone calls, or other), what sorts of comments/remarks were made? (Please check all that apply)

Appearance

Race

Sexual Orientation

Sexual Activity

Intelligence

Self-worth 
Religion

Social status

Other: Please describe.

I have never been cyberbullied

40. If you have been the victim of cyberbullying, what was the reason someone did this to you? (If you have never been a victim of cyberbullying, please select decline to answer)

41. What do you think the motive was for someone to cyberbully you? (Please check all that apply):

Jealousy

Anger

Revenge

Just to be mean/hurtful

To embarrass you

Other: Please describe:

I have never been cyberbullied.

\section{IMPACT/COPING}

42. If you were the victim of cyberbullying, how did it impact you? (If you have never been a victim of cyberbullying, please select decline to answer)

43. If you were a victim of cyberbullying, did you do any of the following things as a result of being cyberbullied? (Please select all that apply)

Avoid friends/peers

Tell someone what was happening (friends, family, trusted adult, etc.)

Miss class

Stop going to activities you once attended

Lose interest in things

Grades dropped in school

Acted out behaviors (e.g. stealing, truancy, substance use, etc.)

Drop-out of school

Drink alcohol/use illegal drugs

Get revenge

Consciously avoid the internet/cell phones

Carry a weapon or something to defend yourself

Other: Please describe:

I have never been cyberbullied.

44. If you were a victim of cyberbullying, how did you cope with the experience? (If you have never been a victim of cyberbullying, please select decline to answer) 
45. If you were a victim of cyberbullying, did you do any of the following things to cope? (Please select all that apply):

Talk about the experience with a friend

Talk about the experience with a parent or trusted adult

Ignore it

Stay off the Internet and/or your cell phone

Remove personal information from certain websites (particularly social networking sites)

Blocked certain people from contacting you on the internet and/or your cell phone

Confront the person doing it

Ask the person doing it to stop

Sent mean, harassing, or embarrassing information back

Use physical force to convince the person to stop (beat them up)

Contact the police

Contact your service provider

Change your phone number, email address, or other identifying information

Other: Please describe:

I have never been cyberbullied.

46. If you were a victim of cyberbullying, how did you get the harassment to stop? Please describe: (If you have never been a victim of cyberbullying, please select decline to answer.)

47. If you were a victim of cyberbullying, how have you been impacted? (If you have never been a victim of cyberbullying, please select decline to answer.)

a. I felt sad or hurt

1-Never 2-Once/twice 3-A few times 4-Many times 5-Almost every day

b. I felt angry

1-Never 2-Once/twice 3-A few times 4-Many times 5-Almost every day

c. I felt embarrassed

1-Never 2-Once/twice 3-A few times 4-Many times 5-Almost every day

d. I felt afraid

1-Never 2-Once/twice 3-A few times 4-Many times 5-Almost every day

e. I felt anxious

1-Never 2-Once/twice 3-A few times 4-Many times 5-Almost every day

f. I felt helpless and/or hopeless

1-Never 2-Once/twice 3-A few times 4-Many times 5-Almost every day

g. I felt frustrated

1-Never 2-Once/twice 3-A few times 4-Many times 5-Almost every day

h. I was stressed 
1-Never 2-Once/twice 3-A few times 4-Many times 5-Almost every day

f. I missed school because of it

1-Never 2-Once/twice 3-A few times 4-Many times 5-Almost every day

g. I cried

1-Never 2-Once/twice 3-A few times 4-Many times 5-Almost every day

h. I had difficulty concentrating

1-Never 2-Once/twice 3-A few times 4-Many times 5-Almost every day

i. My grades have dropped because of it

1-Never 2-Once/twice 3-A few times 4-Many times 5-Almost every day

j. I became jumpy or irritable

1-Never 2-Once/twice 3-A few times 4-Many times 5-Almost every day

$\mathrm{k}$. I thought about the online harassment almost constantly

1-Never 2-Once/twice 3-A few times 4-Many times 5-Almost every day

i. I acted out

1-Never 2-Once/twice 3-A few times 4-Many times 5-Almost every day

j. I blamed myself

1-Never 2-Once/twice 3-A few times 4-Many times 5-Almost every day

$\mathrm{k}$. I had thoughts of suicide

1-No 2-Yes, without a plan 3-Yes, with a plan 4-Yes, with an attempt 


\section{APPENDIX B}

Painful and Provocative Events Scale (PPES) and Additional Items

Please answer the following questions for any time in the past.

For each question circle ONE answer.

\begin{tabular}{|c|c|c|c|c|c|}
\hline & Never & Once & $\begin{array}{c}\text { On } \\
\text { Occasion }\end{array}$ & Sometimes & Regularly \\
\hline Have you gone skydiving? & 1 & 2 & 3 & 4 & 5 \\
\hline Have you gone rock climbing? & 1 & 2 & 3 & 4 & 5 \\
\hline $\begin{array}{l}\text { Have you participated in contact } \\
\text { sports (e.g., tackle football, hockey, } \\
\text { wrestling, martial arts)? }\end{array}$ & 1 & 2 & 3 & 4 & 5 \\
\hline Did you get a tattoo? & 1 & 2 & 3 & 4 & 5 \\
\hline Did you get a piercing? & 1 & 2 & 3 & 4 & 5 \\
\hline $\begin{array}{l}\text { 6. Have you been a victim of physical } \\
\text { abuse? }\end{array}$ & 1 & 2 & 3 & 4 & 5 \\
\hline $\begin{array}{l}\text { 7. Have you been a victim of sexual } \\
\text { abuse? }\end{array}$ & 1 & 2 & 3 & 4 & 5 \\
\hline $\begin{array}{l}\text { 8. Have you been a witness to physical } \\
\text { abuse? }\end{array}$ & 1 & 2 & 3 & 4 & 5 \\
\hline $\begin{array}{l}\text { 9. Have you been a witness to sexual } \\
\text { abuse? }\end{array}$ & 1 & 2 & 3 & 4 & 5 \\
\hline $\begin{array}{l}\text { 10. Have you ever imagined killing } \\
\text { yourself? }\end{array}$ & 1 & 2 & 3 & 4 & 5 \\
\hline 11. Have you shot a gun? & 1 & 2 & 3 & 4 & 5 \\
\hline 12. Have you tied a noose? & 1 & 2 & 3 & 4 & 5 \\
\hline 13. Have you had surgery? & 1 & 2 & 3 & 4 & 5 \\
\hline 14. Have you used intravenous drugs? & 1 & 2 & 3 & 4 & 5 \\
\hline 15. Have you broken a bone? & 1 & 2 & 3 & 4 & 5 \\
\hline 16. Have you been arrested? & 1 & 2 & 3 & 4 & 5 \\
\hline 17. Have you dissected animals? & 1 & 2 & 3 & 4 & 5 \\
\hline 18. Have you gone bungee jumping? & 1 & 2 & 3 & 4 & 5 \\
\hline $\begin{array}{l}\text { 19. Have you participated in illegal } \\
\text { activity (even if you didn't get } \\
\text { caught)? }\end{array}$ & 1 & 2 & 3 & 4 & 5 \\
\hline 20. Have you been in physical fights? & 1 & 2 & 3 & 4 & 5 \\
\hline $\begin{array}{l}\text { 21. Have you jumped from high places } \\
\text { (e.g., cliffs, roofs, balconies)? }\end{array}$ & 1 & 2 & 3 & 4 & 5 \\
\hline $\begin{array}{l}\text { 22. Have you had injuries requiring } \\
\text { medical attention? }\end{array}$ & 1 & 2 & 3 & 4 & 5 \\
\hline 23. Have you been stabbed? & 1 & 2 & 3 & 4 & 5 \\
\hline 24. Have you been shot? & 1 & 2 & 3 & 4 & 5 \\
\hline
\end{tabular}




\begin{tabular}{|c|c|c|c|c|c|}
\hline & Never & Once & $\begin{array}{c}\text { On } \\
\text { Occasion }\end{array}$ & Sometimes & Regularly \\
\hline $\begin{array}{l}\text { 25. Have you had a serious acute } \\
\text { medical condition (e.g. Stroke, } \\
\text { Heart Attack)? }\end{array}$ & 1 & 2 & 3 & 4 & 5 \\
\hline $\begin{array}{l}\text { 26. Have you suffered from a chronic } \\
\text { disease (e.g. Cancer, Diabetes)? }\end{array}$ & 1 & 2 & 3 & 4 & 5 \\
\hline $\begin{array}{l}\text { 27. Have you been hospitalized for } \\
\text { alcohol poisoning or drug overdose? }\end{array}$ & 1 & 2 & 3 & 4 & 5 \\
\hline $\begin{array}{l}\text { 28. Have you been involved in a motor } \\
\text { vehicle accident in which someone } \\
\text { required medical care? }\end{array}$ & 1 & 2 & 3 & 4 & 5 \\
\hline $\begin{array}{l}\text { 29. Have you suffered from mild } \\
\text { chronic pain? }\end{array}$ & 1 & 2 & 3 & 4 & 5 \\
\hline $\begin{array}{l}\text { 30. Have you suffered from moderate } \\
\text { chronic pain? }\end{array}$ & 1 & 2 & 3 & 4 & 5 \\
\hline $\begin{array}{l}\text { 31. Have you suffered from severe } \\
\text { chronic pain? }\end{array}$ & 1 & 2 & 3 & 4 & 5 \\
\hline $\begin{array}{l}\text { 32. Have you experienced a natural } \\
\text { disaster (e.g. flood, tornado, } \\
\text { hurricane, wildfire) where you felt } \\
\text { your life was at risk? }\end{array}$ & 1 & 2 & 3 & 4 & 5 \\
\hline $\begin{array}{l}\text { 33. Have you been the victim of a house } \\
\text { fire? }\end{array}$ & 1 & 2 & 3 & 4 & 5 \\
\hline $\begin{array}{l}\text { 34. Have you (or your significant other) } \\
\text { had a miscarriage? }\end{array}$ & 1 & 2 & 3 & 4 & 5 \\
\hline $\begin{array}{l}\text { 35. Have you (or your significant other) } \\
\text { had an abortion? }\end{array}$ & 1 & 2 & 3 & 4 & 5 \\
\hline $\begin{array}{l}\text { 36. Have you been the victim of a } \\
\text { violent crime (e.g. robbery, assault, } \\
\text { stalking)? }\end{array}$ & 1 & 2 & 3 & 4 & 5 \\
\hline $\begin{array}{l}\text { 37. Have you been a witness of a } \\
\text { violent crime (e.g. robbery, assault, } \\
\text { stalking)? }\end{array}$ & 1 & 2 & 3 & 4 & 5 \\
\hline $\begin{array}{l}\text { 38. Have you witnessed the death of } \\
\text { another person? }\end{array}$ & 1 & 2 & 3 & 4 & 5 \\
\hline $\begin{array}{l}\text { 39. Have you experienced the suicide } \\
\text { attempt of a close personal friend or } \\
\text { family member? }\end{array}$ & 1 & 2 & 3 & 4 & 5 \\
\hline $\begin{array}{l}\text { 40. Have you experienced the suicide } \\
\text { completion of a close personal } \\
\text { friend or family member? }\end{array}$ & 1 & 2 & 3 & 4 & 5 \\
\hline $\begin{array}{l}\text { 41. Have you experienced the death of a } \\
\text { family member? }\end{array}$ & 1 & 2 & 3 & 4 & 5 \\
\hline 42. Have you experienced the death of a & 1 & 2 & 3 & 4 & 5 \\
\hline
\end{tabular}




\begin{tabular}{|c|c|c|c|c|c|}
\hline & Never & Once & $\begin{array}{c}\text { On } \\
\text { Occasion }\end{array}$ & Sometimes & Regularly \\
\hline close personal friend? & & & & & \\
\hline $\begin{array}{l}\text { 43. Have you been a victim of face-to- } \\
\text { face bullying? }\end{array}$ & 1 & 2 & 3 & 4 & 5 \\
\hline $\begin{array}{l}\text { 44. Have you been a victim of } \\
\text { cyberbullying (e.g over the phone, } \\
\text { through text message, online)? }\end{array}$ & 1 & 2 & 3 & 4 & 5 \\
\hline 45. Have you hunted animals? & 1 & 2 & 3 & 4 & 5 \\
\hline 46. Have you trapped animals? & 1 & 2 & 3 & 4 & 5 \\
\hline $\begin{array}{l}\text { 47. Have you responded to an } \\
\text { emergency as an EMT, Police } \\
\text { Officer, or Firefighter? }\end{array}$ & 1 & 2 & 3 & 4 & 5 \\
\hline 48. Have you been in military combat? & 1 & 2 & 3 & 4 & 5 \\
\hline 49. Have you gone whitewater rafting? & 1 & 2 & 3 & 4 & 5 \\
\hline $\begin{array}{l}\text { 50. Have you raced a motor vehicle } \\
\text { (e.g. car, 4-wheeler, dirtbike)? }\end{array}$ & 1 & 2 & 3 & 4 & 5 \\
\hline $\begin{array}{l}\text { 51. Have you gone caving/ spelunking } \\
\text { (exploring wild caves)? }\end{array}$ & 1 & 2 & 3 & 4 & 5 \\
\hline $\begin{array}{l}\text { 52. Have you purposely injured } \\
\text { yourself (e.g. cutting, burning, } \\
\text { erasing)? }\end{array}$ & 1 & 2 & 3 & 4 & 5 \\
\hline $\begin{array}{l}\text { 53. Have you played violent video } \\
\text { games? }\end{array}$ & 1 & 2 & 3 & 4 & 5 \\
\hline 54. Have you watched violent movies? & 1 & 2 & 3 & 4 & 5 \\
\hline
\end{tabular}

